\title{
Les ingrédients à base de protéines laitières : obtention, propriétés et utilisations
}

\author{
J.C. Vuillemard, S. Gauthier et P. Paquin
}

Groupe de recherche en sciences et technologie du lait (STELA), Faculté des Sciences de l'agriculture et de l'alimentation, Université Laval, Québec, (Qué.) Canada G1K $7 P 4$

(reçu le 28 novembre 1988, accepté le 3 mars 1989)

Résumé - Les propriétés fonctionnelles des protéines laitières sont étroitement dépendantes de leurs propriétés physico-chimiques (poids moléculaire, nature et distribution des acides aminés, charge nette), de leur environnement ( $\mathrm{pH}$, température, force ionique, concentration) et du procédé qui leur a été appliqué (chauffage, pompage, séchage, modifications physiques, chimiques ou enzymatiques).

En raison de leur nature amphiphile, les caséines possèdent à l'état natif de bonnes propriétés de tension de surface, ce qui en fait de bons agents émulsifiants et moussants. Les propriétés les plus remarquables des protéines du lactosérum à l'état natif sont leur solubilité au point isoélectrique et leur capacité de former un gel suite à un traitement de chaleur.

La poudre de lait écrémé et la poudre de lactosérum sont les sources traditionnelles de protéines laitières utilisées comme ingrédients alimentaires. En raison d'une teneur élevée en lactose et en minéraux, d'une faible teneur en protéines et de propriétés fonctionnelles déficientes, la poudre de lactosérum est relativement peu utilisée comme ingrédient alimentaire. Différents traitements physiques (précipitation thermique, acide ou par les polyélectrolytes, ultrafiltration, osmose inverse, chromatographie), chimiques (acétylation, succinylation, estérification, phosphorylation) ou enzymatiques permettent de concentrer et/ou de séparer les protéines du lait et de modifier leurs propriétés fonctionnelles. II est ainsi possible de créer une gamme d'ingrédients possédant des propriétés fonctionnelles bien spécifiques. Ces ingrédients peuvent remplacer d'autres types d'ingrédients alimentaires, comme les œufs ou les protéines de soja, ou les compléter d'un point de vue fonctionnel et nutritionnel.

Les récents travaux sur les propriétés d'ordre physiologique et thérapeutique de certaines séquences des caséines laissent entrevoir de nouveaux développements au niveau de la séparation et des propriétés des peptides de protéines laitières ainsi que de nouvelles utilisations dans les domaines médical, parapharmaceutique et en cosmétologie.

protéines laitières - propriétés physico-chimiques - propriétés fonctionnelles - concentration - séparation - modification - ingrédients

Summary - Milk proteins as food ingredients. Functional properties of milk proteins are closely related to their physico-chemical properties (molecular weight, amino acid composition and distribution, net surface charge), to their environment ( $\mathrm{pH}$, temperature, ionic strength, concentration) and to their process (heating, pumping, drying, physical, chemical or enzymatic modification).

Among the milk proteins, caseins show good surface properties in the native state. Because of their amphiphilic structure, they are good foaming and emulsifying agents. The important properties 
of whey proteins are their solubility in the native state at the isoelectric point and their ability to form gels after heat treatment.

Skim milk powder and whey powder are the traditional sources of milk proteins used as food ingredients. However, since whey powder contains high levels of salts and lactose, and low level of proteins, its use as functional ingredient is limited. Physical treatments (heating, acid or polyelectrolytes precipitation, ultrafiltration, reverse osmosis, chromatographic techniques) as well as chemical (acylation, succinylation, esterification, phosphorylation) and enzymatic modification may concentrate and/or fractionate milk proteins and thus modify their functional properties. Therefore, it is possible to produce new food ingredients with specific functional properties which could replace existing food ingredients such as eggs or soy proteins. Furthermore, these ingredients could enhance the functionality and nutritional quality of existing food ingredients.

Recent advances in the field of physiological and therapeutic properties of casein peptides indicate that there is a good market for these peptides in the medical and cosmetic industry.

milk proteins - physico-chemical properties - functional properties - concentration separation - modification - ingredients

\section{INTRODUCTION}

De nos jours, dans le domaine alimentaire et à l'échelle industrielle, il est plus facile d'utiliser des produits secs en vue de la fabrication de denrées alimentaires. L'usage de certains produits sous forme séchée tels les œufs présente cependant certaines limites, particulièrement au niveau de la reproductibilité et de la qualité de l'albumen séché, qui varie de très bonne à médiocre (West, 1984). Ceci a conduit à explorer d'autres sources de protéines possédant de bonnes propriétés fonctionnelles et pouvant être utilisées comme ingrédient alimentaire. Les protéines laitières possédant certaines propriétés fonctionnelles de base intéressantes, une valeur nutritionnelle élevée et leur séchage étant relativement facile, de nombreuses études portant sur le fractionnement ou l'application de divers traitements aux protéines laitières en vue de leur utilisation à titre d'ingrédient alimentaire ont vu le jour.

De plus, d'autres facteurs ont contribué au développement de bases protéiques d'origine laitière. Bien que la production laitière mondiale ait été en baisse pour la première fois en 1987 (Dijkstra, 1988), sa croissance a été constante durant les 25 dernières années pour une production annuelle de l'ordre de 450 millions de tonnes, soit environ 13 millions de tonnes de protéines dont $18 \%$ se retrouvent sous forme de poudre (Tinbergen, 1988). La pression de la législation au niveau de l'élimination de la charge polluante du lactosérum, la concurrence d'autres ingrédients alimentaires (protéines de soja) et le besoin de l'industrie alimentaire en ingrédients alimentaires possédant des propriétés fonctionnelles très spécifiques sont autant de raisons qui ont conduit à modifier les propriétés fonctionnelles des ingrédients laitiers existants ou en produire de nouveaux.

Cette revue, dont le but est de faire le point sur les différents types de dérivés de protéines laitières existants et leur utilisation dans le domaine alimentaire mais aussi dans le domaine médical et parapharmaceutique, s'adresse aux personnes œuvrant dans ces domaines, que ce soit au niveau de la formulation ou de la recherche. Après un rappel des principales propriétés physico-chimiques des protéines du lait, desquelles découlent les propriétés fonctionnelles et certaines 
caractéristiques permettant leur séparation, nous nous proposons de décrire les méthodes de fabrication, les propriétés et les applications des différents types d'ingrédients à base de protéines laitières. Finalement, nous verrons comment il est possible de modifier les propriétés fonctionnelles ou d'obtenir certaines propriétés d'ordre thérapeutique et physiologique des protéines par divers traitements physiques, chimiques ou enzymatiques.

\section{PRINCIPALES PROPRIÉTÉS PHYSICO- CHIMIQUES ET FONCTIONNELLES DES PROTÉINES LAITIĖRES}

Dans cette partie, nous nous attarderons uniquement aux principales différences physico-chimiques et fonctionnelles existant entre les caséines et les protéines du lactosérum.

Les propriétés physico-chimiques et fonctionnelles des protéines laitières (caséines et protéines du lactosérum) ont été abondamment et très bien décrites par Cheftel \& Lorient (1982); Eigel et al. (1984); Kinsella (1984); Modler (1985a et 1985b); Morr (1982, 1985); Swaisgood (1982).

D'après Kinsella (1987), les propriétés fonctionnelles des protéines résultent de l'ensemble des propriétés physico-chimiques et structurales du composé, lesquelles dépendent de son environnement $(\mathrm{pH}$, température, force ionique, nature des ions, concentration, etc.) ainsi que de certains effets dus au procédé (modification physique, chimique, enzymatique, agitation, mélange, réfrigération, chauffage, pompage, entreposage etc.). Les caractéristiques physico-chimiques d'une protéine sont le poids moléculaire, la composition et la distribution des acides ami- nés, la conformation, la charge nette de surface.

D'après Cheftel et al. (1985), les propriétés fonctionnelles des protéines peuvent être classées en 3 groupes principaux :

- propriśtés dépendant des interactions protéine-eau (absorption et rétention d'eau, mouillabilité, gonflement, adhésion, dispersibilité, solubilité et viscosité);

- propriétés dépendant des interactions protéine-protéine (précipitation, gélification);

- propriétés de surface (propriétés émulsifiantes et moussantes).

Certaines de ces propriétés existent déjà naturellement ou s'acquièrent ou sont améliorées au cours de traitements technologiques.

La structure spatiale des caséines est très différente de celle des protéines du lactosérum. La structure des caséines est très ouverte, en raison d'une teneur élevée en proline distribuée uniformément, qui limite la formation d'hélice $\alpha$ et de feuillet $\beta$ (Modler, 1985a; Morr, 1985). II en résulte un état conformationnel très ouvert, insensible à la dénaturation thermique, mais d'accès facile pour les enzymes. II faut également remarquer le rôle joué par la nature et la distribution des acides aminés ainsi que par le nombre et la position de certains groupements tels que les résidus phosphorylés et glycosylés au niveau des propriétés fonctionnelles des caséines. La distribution des 8 groupements phosphates localisés entre les acides aminés 42 et 80 ainsi que la répartition des acides aminés confèrent à la caséine $\alpha_{s 1}$ une région très hydrophile et 3 régions hydrophobes. La caséine $\beta$ possède une extrémité $\mathrm{N}$ terminale hydrophile et une extrémité $\mathrm{C}$ terminale hydrophobe. La nature amphiphile de ces 2 protéines et de la caséine $\chi$ leur confère donc une facilité de s'orienter et 
de diffuser aux interfaces huile-eau ou air-eau, de laquelle découle de bonnes propriétés émulsifiantes et moussantes (Modler, 1985a).

Au contraire, la structure et les propriétés des protéines du lactosérum diffèrent de celles des caséines par une distribution uniforme des acides aminés acides et basiques hydrophiles et hydrophobes le long de la chaîne polypeptidique. De plus, une faible concentration de proline et la présence de liaisons disulfures confèrent aux protéines du lactosérum une conformation globulaire très compacte (Modler, 1985b). La structure secondaire de ces protéines comprendrait $10 \%$ d'hélice $\alpha$, $30 \%$ de feuillet $\beta$ et $60 \%$ de pelote statistique (Ribadeau-Dumas, 1981). Comparées au caséines, les protéines du lactosérum se trouvent à l'état soluble. Dans les conditions de concentration et de force ionique du lait, elles ne précipitent pas au point isoélectrique, mais sont peu stables à la chaleur et précipitent au cours d'un traitement thermique dans l'ordre suivant : immunoglobulines, $\beta$-lactoglobuline, sérum albumine et $\alpha$-lactalbumine (Morr, 1985). Aux environs de la température de dénaturation, la structure de la protéine s'ouvre et se déroule. Cette réaction peut être réversible, mais la plupart du temps les protéines dénaturées irréversiblement s'aggrègent et précipitent (De Wit, 1981). Sous certaines conditions, les protéines dénaturées peuvent donner naissance à un gel (Morr, 1985; Modler, 1985b; Ribadeau-Dumas, 1981; De Wit, 1981).

Le caractère amphiphile des protéines laitières leur permet de s'orienter à l'interface huile-eau ou air-eau et d'abaisser la tension de surface. Par exemple, dans une émulsion ou une mousse, les protéines vont migrer vers l'interface, où elles vont former un film et perdre une partie de leur énergie de conformation et d'hydratation, d'où une diminution de la tension de surface (Kinsella, 1984). La stabilité du système va être fortement dépendante de la nature et des propriétés du film (facteurs stériques et électrostatiques, épaisseur, élasticité et viscosité du film) (Kinsella, 1984).

Les différences physico-chimiques fondamentales entre les caséines et les protéines du lactosérum (répartition des zones hydrophiles et hydrophobes, structure tertiaire, présence de groupements sulfhydryles libres) se reflètent au niveau des propriétés fonctionnelles.

La structure plus làche des caséines ainsi que la localisation distincte des zones hydrophobes et hydrophiles leur confèrent un caractère plus amphiphile que les protéines du lactosérum (Morr, 1982). Les caséines peuvent pénétrer facilement les surfaces sans se déplier, d'où une vitesse de diminution de tension de surface élevée, corrélée avec les propriétés moussantes (Kitabatake et Doi, 1982). La capacité émulsifiante de la poudre de lait écrémé est supérieure à celle des caséinates, en raison de l'état moléculaire respectif de la caséine dans les deux types de produits et de la présence de protéines du lactosérum qui améliore la force des films interfaciaux (Kinsella, 1984). La caséine $\beta$ est la plus efficace pour diminuer la tension de surface, puis la caséine $\alpha_{\mathrm{s}}$, puis la $\chi$ (Fox \& Mulvihill, 1983).

La solubilité sur toute l'échelle de $\mathrm{pH}$ et la capacité de rétention d'eau sont les propriétés fonctionnelles les plus remarquables des protéines du lactosérum. D'après De Moor \& Huyghebaert (1987), la poudre de lactosérum doux peut absorber $3,9 \mathrm{~g}$ d'eau par $\mathrm{g}$ de protéine contre $2,6 \mathrm{~g}$ et $3,0 \mathrm{~g}$ d'eau par $\mathrm{g}$ de protéine pour les caséinates de sodium et de calcium, respectivement. De cette capacité de lier et structurer l'eau découlent des propriétés fondamentales pour l'industrie alimen- 
taire, tant au plan technologique (bon déroulement des processus enzymatiques) qu'au plan économique (conservation de l'eau tout au long de la chaîne de production et de commercialisation). Les variations de composition des protéines du lactosérum entre elles leur confèrent des différences au niveau de leurs propriétés fonctionnelles. En raison de son poids moléculaire élevé, la sérum albumine possède de faibles propriétés fonctionnelles. Quant à l' $\alpha$-lactalbumine et la $\beta$ lactoglobuline, les résultats sont parfois contradictoires. D'après Closs \& Lorient (1988), la $\beta$-lactoglobuline montre les meilleures propriétés de tension de surface, qui peuvent être améliorées par dénaturation à la chaleur ou par protéolyse. Ceci est confirmé par les travaux de Slack et al. (1986b), qui ont montré que les propriétés émulsifiantes (capacité et stabilité) de la $\beta$-lactoglobuline sont supérieures à celles de l' $\alpha$-lactalbumine. Au contraire, d'après Reimerdes \& Lorenzen (1983) et De Wit et al. (1988), l' $\alpha$-lactalbumine confère à l'émulsion une stabilité 3 à 4 fois supérieure à celle obtenue avec la $\beta$-lactoglobuline. Selon Evans (1986), la fraction protéose-peptone des protéines du lactosérum possède une excellente capacité moussante. Une description plus complète des propriétés fonctionnelles des protéines laitières a été publiée par Cheftel \& Lorient (1982).

Poưr posséder de bonnes propriétés fonctionnelles, la protéine doit donc être soluble, amphiphile et doit pouvoir s'orienter et changer de conformation facilement, tout en conservant quelques résidus de structure tertiaire (Kinsella, 1984).

Les méthodes d'évaluation des propriétés fonctionnelles des protéines alimentaires et laitières ont été abondamment décrites par Kinsella (1984), Mulvihill et Fox (1983). Cependant, bien que les propriétés physico-chimiques des constituants du lait soient assez bien connues, les connaissances concernant leur comportement fonctionnel restent limitées. En effet, Mulvihill \& Fox (1983) et Kinsella (1987) déplorent l'absence de méthodes officielles d'évaluation des propriétés fonctionnelles des protéines alimentaires. De plus, ces propriétés variant avec le $\mathrm{pH}$, la température, la concentration, la force ionique, la constante diélectrique du milieu, les interactions avec les autres composés, le procédé, etc., il n'est pas surprenant que les résultats rapportés dans la littérature soient souvent contradictoires et il est donc difficile d'extrapoler. Des comités désignés par la Fédération internationale de laiterie tentent actuellement de définir des méthodes standards d'évaluation des propriétés fonctionnelles. II faut noter qu'une méthode officielle d'évaluation de la solubilité et de la réhydratation des protéines laitières vient d'être publiée récemment (FIL, 1987). De Wit et al. (1988) ont récemment publié une méthodologie complète d'évaluation des propriétés fonctionnelles des protéines laitières.

\section{PRINCIPAUX TYPES D'INGRÉDIENTS ALIMENTAIRES À BASE DE PRO- TÉINES LAITIĖRES : OBTENTION, PROPRIÉTÉS ET APPLICATIONS}

Pour avoir du succès, un ingrédient alimentaire protéique doit répondre aux critères suivants :

- posséder de bonnes propriétés fonctionnelles et nutritionnelles;

- avoir une concentration protéique élevée;

- supporter les étapes de transformation, conditionnement et conservation sans changement majeur;

- être compatible avec les autres ingrédients du produit; 
- être dépourvu de micro-organismes pathogènes et de facteurs toxiques ou antinutritionnels;

- être dépourvu de saveurs indésirables et de pigments;

- être produit à faible coût et avec une bonne reproductibilité.

Les ingrédients laitiers intégrés dans la composition d'un aliment le sont principalement sous forme de poudre. II peut s'agir de poudre de lait ou de lactosérum séchés sans traitement préalable. Cependant, la tendance est à l'utilisation d'ingrédients provenant de la concentration et du fractionnement du lait écrémé ou du lactosérum.

\section{Poudre de lait entier}

En raison de son coût élevé et du développement de saveurs indésirables par oxydation de la matière grasse au cours de la conservation, la poudre de lait entier est relativement peu utilisée comme ingrédient. L'addition de lécithine permet cependant de maintenir une saveur adéquate à la poudre de lait entier (Modler, 1985a).

A l'exception de l'incorporation de la poudre de lait entier séchée par atomisation en boulangerie pour l'apport de matière grasse ou d'agents émulsifiants, son utilisation comme ingrédient se limite essentiellement à la fabrication du chocolat. La matière grasse laitière est un des éléments les plus importants entrant dans la composition du chocolat au lait. En raison de sa compatibilité avec le beurre de cacao, elle est capable de former une phase continue. De plus, elle contribue à la saveur douce et à la texture du chocolat et elle est moins coûteuse que le beurre de cacao. D'autre part, la poudre de lait entier améliore la valeur nutritive du chocolat et lui confère sa couleur claire.

II faut noter que l'industrie du chocolat est un des derniers utilisateurs de poudre de lait séchée sur rouleaux. Les raisons en sont la destruction supérieure des micro-organismes, l'inactivation des enzymes lipolytiques et une saveur supérieure (Edwards, 1984). D'après Verhey (1986), lors du séchage par atomisation, une partie de la matière grasse conserve sa structure globulaire et ne se mélange pas à la phase continue de matière grasse, si bien qu'une quantité additionnelle de $2-3 \%$ de beurre de cacao (ingrédient très onéreux) est nécessaire pour maintenir les propriétés organoleptiques du produit final. Les progrès au niveau du séchage par atomisation permettent cependant de produire actuellement des poudres de lait entier adaptées à la fabrication du chocolat (Pasquet, 1988).

\section{Poudre de lait écrémé}

Par comparaison avec la poudre de lait entier, le poudre de lait écrémé est peu utilisée pour la fabrication du chocolat, ou alors en association avec l'huile de beurre dans le but de réduire la quantité de beurre de cacao (Campbell \& Pavlasek, 1987). La poudre de lait écrémé est incorporée à une variété de produits, en raison de sa solubilité, de sa capacité émulsifiante et de rétention d'eau (Modler, 1985a). Le produit est disponible sous 3 formes : low, medium et high-heat. Ce classement d'après le traitement de chaleur appliqué au lait représente indirectement le taux de dénaturation des protéines du lactosérum, qui se traduit par leur insolubilité. La quantité de protéines insolubles du lactosérum doit être inférieure à $25 \%$ et supérieure à $81 \%$ de la quantité de protéines 
du lactosérum totale pour les poudres low-heat et high-heat, respectivement. La teneur moyenne en protéines du lactosérum étant de $8-9 \mathrm{mg} / \mathrm{g}$ de solides totaux non gras, la quantité de protéines solubles du lactosérum sera supérieure à $6 \mathrm{mg} / \mathrm{g}$, entre 6 et $1,6 \mathrm{mg} / \mathrm{g}$ et inférieure à $1,5 \mathrm{mg} / \mathrm{g}$ de poudre low-heat, mediumheat et high-heat, respectivement (Knipschildt, 1986).

Les poudres low-heat contiennent une faible quantité de protéines dénaturées et sont utilisées dans des produits où les propriétés de solubilité, de gélification, d'émulsion et une faible dénaturation des protéines sont importantes (fortification du yoghourt, fromage fait de lait reconstitué, crème et desserts glacés, soupes déshydratées et congelées, sauces déshydratées et sauces à salade) (Noznick, 1982; Modler, 1985a).

Les poudres medium-heat possèdent une bonne capacité de liaison d'eau et d'activité de surface et sont utilisées dans la crème glacée, les desserts congelés, les soupes congelées, la crème acidifiée etc.

Les poudres high-heat sont hautement dénaturées et peu solubles, la capacité de liaison d'eau est augmentée et le facteur antigonflement du pain réduit. En raison de sa faible solubilité et de la réduction de l'effet dépresseur sur la pâte à pain, ce type de poudre trouve une utilisation dans les produits structurés (boulangerie, biscuiterie, confiserie et salaisonnerie) et contribuent à la cohésion, la texture, la saveur, la couleur et la valeur nutritive du produit (Modler, 1985a; Campbell \& Pavlasek, 1987).

Les principales sources de variation des poudres de lait écrémé proviennent essentiellement des différences de composition du lait, des prétraitements (concentration, degré de cristallisation du lactose et température de séchage) ainsi que du type de séchage. D'autres traitements sont relativement rares. II faut signaler les poudres à teneur réduite en calcium, qui améliorent la saveur, la texture, la liaison de l'eau dans la viande et dans les produits tartinables (Modler, 1985a).

\section{Poudre de babeurre}

La composition de la poudre de babeurre est sensiblement équivalente à celle de la poudre de lait écrémé. Incorporée au chocolat, elle contribue à sa saveur caractéristique ainsi qu'à l'émulsion (Campbell \& Pavlasek, 1987). En boulangerie, elle est incorporée dans les cakes pour sa saveur et le jaunissement du gluten (Cocup \& Sanderson, 1987).

\section{Poudre de lactosérum}

Le lactosérum résultant de la fabrication fromagère contient environ $20 \%$ des protéines laitières totales (Modler, 1985b). Les progrès dans le domaine du séchage par atomisation ont permis de produire de la poudre de lactosérum non hygroscopique mais avec une proportion plus ou moins grande de protéines non dénaturées, suivant le type de poudre (highheat, medium-heat ou low-heat).

Les protéines des poudres de lactosérum high-heat sont hautement dénaturées et relativement insolubles et sont utilisées dans des aliments où la solubilité est indésirable ou non nécessaire (produits de boulangerie, pâtes, céréales de petitdéjeuner, etc.).

Les poudres low-heat contiennent des protéines très solubles et sont utilisées dans les produits alimentaires où la 
saveur, la couleur, la stabilité physique et la solubilité sont requises.

Les propriétés des poudres de lactosérum dépendent également du type de lactosérum (doux ou acide) et des traitements qu'il a pu subir avant le séchage (déminéralisation, cristallisation du lactose, ultrafiltration, etc.).

Les lactosérums doux présentent un certain intérêt pour les produits de cuisson céréaliers. La composition en acides aminés des protéines du lactosérum est complémentaire de celle des protéines végétales. De plus, les lactosérums doux améliorent la valeur nutritionnelle et organoleptique des produits finis (De La Guérivière, 1981). Dans certains cas, l'effet de l'amollissement de la pâte constitue une influence positive plutôt que négative dans le processus de fabrication, en affermissant la mie et en améliorant la résistance mécanique, lorsque de la poudre de lactosérum est ajoutée dans les petits pains $(3-6 \%)$, les biscuits $(2-20 \%)$, les pâtes à tarte $(2-10 \%)$.

La déminéralisation du lactosérum a étendu l'emploi de ce produit. L'opération de déminéralisation consiste à retirer, à partir d'un lactosérum doux de très bonne qualité bactériologique contenant très peu d'acide lactique et de minéraux, une partie des ions métalliques et de l'acide lactique. Généralement, cette opération est effectuée par électrodialyse ou par échange d'ions. II en résulte un produit contenant peu de minéraux et dont les propriétés organoleptiques ont été améliorées. De plus, une déminéralisation poussée suivie d'une acidification à $\mathrm{pH}$ 4,5 permet de se débarrasser de $99 \%$ des bactéries et de clarifier le produit en éliminant $90 \%$ des lipides résiduels (de Wit et de Boer, 1975a). L'absence de lipides résiduels améliore la conservation, le pouvoir moussant et émulsifiant ( $\mathrm{De}$ Wit et Hontelez-Backx, 1981). La déminé- ralisation permet d'augmenter la quantité de lactosérum pouvant être incorporée au pain et en fait un ingrédient particulièrement bien adapté pour la fabrication des produites secs (De La Guérivière, 1981). La poudre de lactosérum déminéralisée est utilisée dans les formules pour nourrissons, dans les aliments diététiques, en confiserie, pâtisserie et peut partiellement remplacer la poudre de lait écrémé dans la crème glacée (Modler, 1985b; Campbell \& Pavlasek, 1987).

La poudre de lactosérum délactosée est, quant à elle, un copoduit de la fabrication du lactose. Pour extraire le lactose, le lactosérum est concentré à $65^{\circ} \mathrm{C}$, refroidi et centrifugé. Les protéines ont donc été partiellement dénaturées par le traitement thermique et la teneur en minéraux rapportée à l'extrait sec est très élevée. Ce produit n'est pas fabriqué pour la préparation d'aliments spécifiques et il est généralement utilisé en alimentation animale. II est cependant possible de réduire considérablement la teneur en minéraux (de 24 à 1-3\%) par solubilisation et lavage à pH 3,5 (Harwalkar et Emmons, 1969).

\section{Les caséines et caséinates}

La préparation de caséine résulte d'une succession de traitements, qui sont la précipitation acide ou la coagulation enzymatique de lait écrémé, la séparation du sérum par tamisage ou décantation centrifuge, le lavage à l'eau et la séparation caséine-eau, généralement sur décanteur centrifuge. Après avoir été pressé et broyé, le produit est séché sur lit fluidisé, sur cylindre, par chauffage à attrition, sur sécheur vibratoire ou par atomisation.

La caséine acide est obtenue par acidification du lait écrémé à $\mathrm{pH} 4,3$ et 43 $45^{\circ} \mathrm{C}$ à l'aide d'acide minéral (chlorhy- 
drique ou sulfurique). Cette précipitation peut être réalisée en continu à partir de 10000 I à raison de $300 \mathrm{~kg} / \mathrm{h}$.

La caséine lactique résulte de la précipitation des caséines, suite à l'acidification du milieu par des cultures mixtes acidifiantes, composées généralement de Streptococcus lactis et/ou cremoris. Après $16 \mathrm{~h}$ de fermentation à $26-27^{\circ} \mathrm{C}$, la température est élevée à $55-65^{\circ} \mathrm{C}$ pour favoriser l'agglomération des particules de caséine (Muller, 1982). L'avantage de la caséine lactique est de contenir 2 à 3 fois moins de chlorures que la caséine chlorhydrique préparée à l'aide d'acide minéral, qui reste cependant la pratique la plus courante. Une préacidification ionique (Triballat, 1979) permet de pallier cet inconvénient. Le passage de lait écrémé sur une résine cationique permet d'obtenir à la fois une déminéralisation et une préacidification jusqu'à pH 4,9-5,0 (Triballat, 1979) ou $\mathrm{pH} 2,5$ (Bridel, 1981) par échange des ions $\mathrm{Ca}, \mathrm{K}$ et $\mathrm{Na}$ du lait avec les ions $\mathrm{H}^{+}$ de la résine. L'acidification finale est ensuite obtenue par addition d'acide minéral jusqu'à $\mathrm{pH}$ 4,5-4,6 (procédé Triballat) ou par mélange avec le reste du lait (procédé Bridel). Contrairement à la poudre de lait et à la caséine présure, la structure micellaire des caséines acide et lactique est détruite par acidification et solubilisation du calcium colloïdal (Kinsella, 1984).

La caséine présure résulte de la coagulation enzymatique des caséines par la pepsine et la chymosine. Après 20 à 30 min de coagulation, la température est élevée à $55-65^{\circ} \mathrm{C}$, comme dans le cas de la caséine acide. La quantité de calcium micellaire est toujours présente dans les caséines présure et, à l'exception de certaines propriétés filantes sous certaines conditions de $\mathrm{pH}$, ce type de caséine insoluble est peu utile d'un point de vue fonctionnel, à moins de complexer le calcium (Morr, 1981).
La neutralisation des précipités insolubles de caséines acide et lactique en sels de sodium, potassium, ammonium ou calcium permet d'obtenir un produit soluble plus communément appelé caséinate.

D'après Morr (1979b), les caséinates, sous forme de sous-unités monomériques ou sous forme d'agrégats, peuvent migrer rapidement à l'interface huile-eau ou aireau des émulsions ou des mousses et les stabiliser contre la coalescence ou l'effondrement. Les caséinates montrent également de bonnes propriétés émulsifiantes, quels que soient le $\mathrm{pH}$ et la force ionique avec un maximum à pH 10,4 (Morr, 1981).

Les propriétés des caséinates sont largement influencées par les procédés de fabrication. Les caséinates de $\mathrm{Na}, \mathrm{K}$ et $\mathrm{NH}_{4}$ sont complètement solubles en dessous de $\mathrm{pH} \mathrm{5,5}$ et forment des solutions visqueuses qui possèdent d'excellentes propriétés fonctionnelles (émulsifiantes, moussantes, épaississantes, absorption d'eau), supérieures à celles du caséinate de calcium, qui reste sous forme de suspension colloïdale et absorbe beaucoup moins d'eau (Morr, 1982). Le caséinate de sodium est incorporé aux produits alimentaires à teneur en eau élevée ou intermédiaire, alors que le caséinate de calcium est incorporé dans les produits à faible teneur en eau. Cependant, en remplaçant le calcium par différentes quantités de sodium, et parfois en $y$ incorporant des protéines du lactosérum, on peut augmenter nettement la stabilité des caséinates de calcium à $\mathrm{pH}$ acide et les incorporer comme agents foisonnants, émulsifiants, stabilisants ainsi que pour leur capacité de rétention d'eau et d'aération dans les aliments dont le $\mathrm{pH}$ est compris entre 0,5 et 5,5 (Modler, 1985a). D'ailleurs, les propriétés des caséinates et des concentrés de protéines de lactosérum sont très complémentaires. Les caséinates possèdent un bon pouvoir 
mulsifiant et sont stables à la chaleur et les concentrés de protéines de lactosérum forment un gel lors de la cuisson, ce qui permet d'utiliser ces ingrédients en complémentarité dans les aliments de cuisson (Sanderson, 1988a).

Les caséines sont utilisées en confiserie pour leur capacité de rétention d'eau (plus de 2 fois leur propre poids) et inhibent ainsi la formation de cristaux de sucre. Elles contribuent également au brunissement des bonbons et au développement de saveurs attribuables aux aldéhydes formés par la réaction de Maillard (Campbell \& Pavlasek, 1987). En dehors de cette utilisation, les caséines présentent peu d'intérêt pour l'industrie alimentaire, en raison de leur difficulté de solubilisation et de dispersibilité. Au contraire, les caséinates de sodium, potassium ou calcium sont utilisés couramment dans les produits alimentaires pour leur solubilité, leur absorption d'eau, leur stabilité à la chaleur, leurs propriétés tensioactives (émulsification, moussage) dues à leur conformation en pelote statistique, leurs propriétés gélifiantes, coagulantes ainsi que pour leur viscosité (Cheftel \& Lorient, 1982; Morr, 1985). Du caséinate de sodium de faible viscosité peut être ajouté lors de la fabrication du yogourt pour standardiser la teneur en protéines et la viscosité (Kjaergaard Jensen et al., 1987). En mélangeant le caséinate de sodium et le caséinate de calcium à différentes concentrations, il est possible d'obtenir toute une gamme de caséinates de viscosité décroissante (Parkinson, 1984). Les caséinates peuvent être incorporés au lait destiné à la fabrication fromagère, jusqu'à concurrence de 5 grammes de protéines par litre de lait mis en œuvre. Cela a pour effet d'améliorer la texture de certains fromages (Segalen, 1981). En raison de leur valeur nutritionnelle et de l'absence de sels (particulièrement le caséinate de calcium), les caséinates sont utilisés dans les produits à caractère diététique et nutritif, tels les beurres et pâtes à tartiner "légers" (McDermott, 1987). En ce qui concerne les produits carnés, l'addition de protéines laitières au moment de la restructuration de la viande de volaille permet de réduire les pertes à la cuisson ainsi que la sensation de viande trop riche. L'étape de désossement mécanique du poulet tend à donner un produit foncé. L'utilisation du caséinate de calcium sous forme d'émulsion permet de le blanchir (Van Den Hoven, 1987). Les caséinates sont utilisés dans les produits restructurés pour leur pouvoir émulsifiant et pour le maintien de la cohésion (Sanderson, 1988c). Ils sont également utilisés pour leur effet blanchissant, stabilisant, émulsifiant, régulateur de viscosité et leur pouvoir de liaison de l'eau dans les produits suivants : imitations de crème à café, mélanges à cakes, desserts, garnitures fouettées, crèmes, céréales de petitdéjeuner, confiserie, sauces déshydratées et sauces à salade, boissons, imitations de fromage et crèmes alcoolisées (Campbell \& Pavlasek, 1987; Cocup \& Sanderson, 1987; Sanderson, 1988b). En combinaison avec d'autres protéines alimentaires (protéines de lactosérum, de soja et de céréales), ils sont utilisés en boulangerie, en pâtisserie et dans les desserts glacés (Morr, 1982; Parkinson, 1984).

\section{Les cryocaséines}

II est possible d'isoler sous forme de précipité plus de $95 \%$ des caséines du lait écrémé par ultrafiltration de lait écrémé (jusqu'à un facteur de concentration de 4 à 6), suivie d'une cryodéstabilisation (congélation du rétentat à $-8^{\circ} \mathrm{C}$ ) et d'une centrifugation du rétentat décongelé à $5000 \mathrm{~g}$ pendant $10 \mathrm{~min}$ (Lonergan, 1983). 
Ce procédé permet d'obtenir des isolats de caséines possédant à la fois une excellente solubilité et une structure micellaire intacte (Moor et al., 1988) et pouvant être utilisés comme ingrédients alimentaires, seuls ou en combinaison avec d'autres protéines (Moor et al., 1989).

\section{Les concentrés de protéines de lacto- sérum}

Le terme concentré de protéines de lactosérum ( $C P L)$ est généralement utilisé pour désigner des produits contenant des teneurs élevées en protéines du lactosérum (de 25 à $95 \%$ de leur poids sec) et préparés selon l'une des techniques de concentration ou de fractionnement suivantes : traitement à la chaleur, ultrafiltration, osmose inverse, chromotographie ou précipitation par les agents complexants. Ces traitements peuvent être combinés à une déminéralisation ou à une cristallisation du lactose (Marshall, 1982).

\section{Concentrés obtenus par précipitation thermique}

Le chauffage d'un lactosérum doux $(\mathrm{pH}$ $6,5)$ à $85-100^{\circ} \mathrm{C}$ pendant $30 \mathrm{~min}$, acidifié dans la zone du point isoélectrique des protéines $(\mathrm{pH} 4,0-4,8)$, lavé, centrifugé puis séché permet de récupérer $95 \%$ des protéines et d'obtenir un produit contenant au moins $80 \%$ de protéines (Creig, 1979). A l'exception du pouvoir de rétention d'eau, les propriétés fonctionnelles du produit obtenu sont relativement faibles en raison de la dénaturation. La solubilité, le pouvoir gélifiant et moussant peuvent néanmoins être améliorés par un traitement alcalin à chaud, mais cela s'accompagne de pertes en valeur nutritionnelle (Jelen \& Schmidt, 1976). Dans certains cas, des sels de calcium sont ajoutés avant l'acidification, ce qui permet d'insolubiliser les protéines (Marshall, 1982). Un procédé en continu a été développé pour précipiter les protéines du lactosérum et les réincorporer au lait destiné à la fabrication fromagère, de manière à augmenter le rendement de 10 à $14 \%$ (procédé "Centri-Whey"). Le lactosérum est chauffé à $97^{\circ} \mathrm{C}$ pendant $20 \mathrm{~min}$, acidifié à $\mathrm{pH}$ $4,7-5,0$, refroidi puis centrifugé.

En raison de leur faible solubilité, ces concentrés sont utilisés pour l'enrichissement protéique des produits de cuisson à base de céréales en boulangerie, dans les pâtes alimentaires, en confiserie, dans les produits carnés et les barres nutritionnelles (Morr, 1982; Campbell \& Pavlasek, 1987). Par acidification préalable du lactosérum à $\mathrm{pH} 5$ sur une résine cationique puis chauffage $15 \mathrm{~min}$ à $92^{\circ} \mathrm{C}$, il est possible d'obtenir un concentré contenant très peu de minéraux et environ $80 \%$ des protéines, destiné à fortifier en protéines les aliments des populations souffrant de malnutrition (Racotta et al., 1981).

Un traitement thermique $15 \mathrm{~min}$ à $95^{\circ} \mathrm{C}$ et à $\mathrm{pH} 2,5-3,5$ ne dénature que partiellement les protéines du lactosérum et accroît la solubilité. Cela permet d'obtenir, après neutralisation et séchage, un produit contenant $40 \%$ de protéines, présentant de bonnes propriétés moussantes, d'absorption d'eau, de viscosité et de gélification ainsi qu'une résistance au brunissement au cours de la stérilisation (Modler \& Emmons, 1977; Modler \& Harwalkar, 1981). Cheftel \& Lorient (1982) proposent l'utilisation de ces produits dans les produits carnés ou les pâtes à tartiner.

Sous certaines conditions, la sensibilité à la chaleur de l' $\alpha$-lactalbumine permet de la séparer de la $\beta$-lactoglobuline. En effet, à bas $\mathrm{pH}$ et sous l'influence d'un faible traitement thermique, les molécules d' $\alpha$-lactalbumine se polymérisent et 
s'agrègent. II est possible, par application d'un traitement thermique de $55^{\circ} \mathrm{C}$ pendant $30 \mathrm{~min}$ à un rétentat de lactosérum préalablement acidifié à $\mathrm{pH} 3,8$, de séparer l' $\alpha$-lactalbumine et la sérum albumine de la $\beta$-lactoglobuline par précipitation et centrifugation, pour arriver à des puretés de $98 \%$ pour la fraction contenant la $\beta$ lactoglabuline avec un rendement de $90 \%$, et $50 \%$ d' $\alpha$-lactalbumine et $15 \%$ de sérum albumine pour l'autre fraction (Pierre \& Fauquant, 1986; Maubois et al., 1987). Un procédé sensiblement analogue, consistant à chauffer du lactosérum à $12 \%$ de solides totaux à $\mathrm{pH} 4,0-4,5$ pendant $5 \mathrm{~min}$ à $64^{\circ} \mathrm{C}$, permet, après refroidissement et séparation, d'obtenir une fraction enrichie en $\alpha$-lactalbumine contenant $47 \%$ de protéines et une fraction enrichie en $\beta$-lactoglobuline contenant $75 \%$ de protéines (Pearce, 1987). Le procédé de Slack et al. (1986a; 1986b), sans traitement de chaleur, comprend une réduction de $90 \%$ du volume du lactosérum par ultrafiltration, une déminéralisation partielle du rétentat, un ajustement du $\mathrm{pH}$ à 4,65 avant et après déminéralisation et une centrifugation à $9000 \mathrm{~g}$ pendant $30 \mathrm{~min}$. Le rendement en protéines obtenu est de $55 \%$ dans le cas d'un lactosérum doux et de $45 \%$ dans le cas d'un lactosérum acide, avec une pureté de l'ordre de 38 à $75 \%$ pour la $\beta$-lactoglobuline et de 28 à $65 \%$ pour l' $\alpha$-lactalbumine. Après avoir été séparée par centrifugation, l' $\alpha$-lactalbumine peut ensuite être resolubilisée à $\mathrm{pH} 6,5$ et conserve $75 \%$ de sa solubilité au point isoélectrique. Quant aux propriétés fonctionnelles, I' $\alpha$ lactalbumine possède de bonnes propriétés fouettantes, mais la stabilité de la mousse est faible, de même que les propriétés émulsifiantes. Les fractions enrichies en $\beta$-lactoglobuline possèdent de faibles propriétés moussantes, mais des propriétés émulsifiantes acceptables (Slack et al., 1986b). La fraction enrichie en $\alpha$-lactalbumine obtenue par Pearce (1987) possède de bonnes propriétés émulsifiantes, car elle contient la plupart des lipides résiduels, dont certains sont liés aux protéines. La présence des immunoglobulines dans la fraction contenant l' $\alpha$-lactalbumine et l'élimination de la majeure partie de la $\beta$-lactoglobuline, qui est la protéine laitière la plus allergène, permet d'utiliser l' $\alpha$-lactalbumine dans les formules pour enfant (Mulvihill \& Fox, 1983; Pearce, 1987; Maubois et Léonil, 1988). En raison de sa solubilité à $\mathrm{pH}$ acide, la $\beta$-lactoglobuline peut être utilisée comme supplément protéique dans les jus de fruits, dans les imitations de crèmes pour le café (Pearce, 1987) ou éventuellement dans les filtres à cigarettes pour sa capacité de piéger les goudrons (Maubois \& Léonil, 1988).

La perte des propriétés fonctionnelles, la difficulté d'ajuster les conditions de chauffage et la température ainsi qu'une centrifugation trop onéreuse offrent peu d'intérêt pour la concentration des protéines du lactosérum par traitement de chaleur. D'autres procédés permettant de concentrer et/ou de séparer les protéines du lactosérum et les caséines ont été mis en œuvre.

\section{Concentrés obtenus par ultrafiltration}

Les procédés de séparation sur membrane, apparus dans les années 60 , ont rapidement pris un essor important pour devenir une des techniques de séparation les plus courantes au niveau industriel. L'ultrafiltration consiste à séparer, sous pression, les macromolécules en solution selon leur taille en employant une membrane appropriée. Si les pores de la membrane sont très petits et la pression très élevée (supérieure à 50 bars), le perméat n'est constitué que d'eau : c'est l'osmose inverse. Si les pores de la membrane sont plus gros et laissent passer les solutés de 
faible poids moléculaire, les substances de haut poids moléculaire sont concentrées : c'est l'ultrafiltration.

II est possible, par diafiltration, c'est-àdire en ajoutant en cours d'opération une quantité d'eau égale à une certaine quantité de rétentat, d'atteindre des concentrations en protéines très élevées (jusqu'à $90 \%)$. Généralement, les concentrés de protéines de lactosérum obtenus par ultrafiltration sont commercialisés sous forme de poudre contenant 30 à $80 \%$ de protéines.

L'avantage principal de l'ultrafiltration est la non-dénaturation des protéines et des enzymes au cours de la concentration. En revanche, au chapitre des inconvénients, il faut citer la concentration des contaminants, qui est à éviter dans le cas de concentrés protéiques destinés aux laits maternisés. La concentration des lipides résiduels ainsi que la concentration de certains métaux catalysant les réactions d'oxydation (fer, cuivre) associés aux protéines peut provoquer l'apparition de saveurs indésirables (De Boer et al., 1977). De plus, la présence de lipides résiduels affecte les propriétés fonctionnelles et peut expliquer que les résultats de certains travaux concernant la substitution des CPL au blanc d'œuf soient contradictoires (De Wit et De Boer, 1975b; Maubois et Brulé, 1982). La matière grasse accélèrerait l'effondrement de la mousse obtenue avec les protéines laitières (Edwards, 1984). De Boer et al. (1977) ont montré que l'élimination des lipides résiduels confère aux $\mathrm{CPL}$ les mêmes propriétés moussantes que le blanc d'œuf. La clarification des lipides résiduels semble la meilleure méthode pour éliminer les défauts de saveur des CPL au cours de la conservation et maintenir les propriétés fonctionnelles (De Wit, 1981). Les phospholipides résiduels peuvent être clarifiés par passage du lactosérum sur une colonne échangeuse d'ions (procédés Sphérosil et Vistec), par précipitation spontanée suite à l'ajustement du pH à 4,6 (De Wit et al., 1983) ou par agrégation des lipoprotéines en présence de calcium ionisé sous l'effet d'un traitement thermique (Fauquant et al., 1985).

\section{Concentrés obtenus par chromatogra- phie d'échange d'ions}

Le procédé Sphérosil est un procédé de séparation des protéines du lactosérum par chromatographie d'échange d'ions. Les Sphérosil sont des billes de silice sur la surface desquelles ont été greffés des groupements échangeurs d'ions. La résine Sphérosil «S" échangeuse de cations forts est utilisée pour la séparation des protéines du lactosérum acide. Les protéines chargées positivement sont retenues sur la résine et éluées par inversion de leur charge, suite à une élution par une solution d'ammoniaque. La résine Sphérosil "QMA" échangeuse d'anions forts est utilisée en association avec une résine échangeuse de cations faibles pour séparer les protéines du lactosérum doux dont le pH est voisin de 6,6. A ce $\mathrm{pH}$, l'ensemble des protéines qui possèdent une charge nette négative est adsorbé sur la résine échangeuse d'anions, à l'exception des immunoglobulines qui possèdent une charge nette positive ou nulle. Les protéines adsorbées sont ensuite détachées, suite à une élution par une solution d'acide chlorhydrique. Les albumines ainsi obtenues pourront être utilisées en alimentation humaine et infantile ou comme ingrédient alimentaire et thérapeutique. Les immunoglobulines sont, quand à elles, retenues sur la colonne échangeuse de cations et éluées par une solution d'ammoniaque. A partir d'un lactosérum doux contenant 5,5 à $6,0 \%$ d'extrait sec, dont 0,55 à $0,58 \%$ de matières protéiques, il est possible d'obtenir, après ultrafiltration et séchage, un 
concentré protéique contenant $96 \%$ d'extrait $\mathrm{sec}$, dont 85 à $90 \%$ de matières protéiques. La composition en protéines est de 5 à $10 \%$ de protéoses peptones, 90 à $95 \%$ d'albumines, dont 65 à $70 \%$ de $\beta$ lactoglobuline, 12 à $15 \%$ d' $\alpha$-lactalbumine et 8 à $10 \%$ de sérum albumine (Mirabel \& Goudal, 1981). La solubilité à pH 6,0 est bonne mais faible à $\mathrm{pH} 4,6$, en raison de la dénaturation des protéines (la $\beta$-lactoglobuline serait la plus atteinte). Le degré de solubilité descend à $79 \%$ pour le concentré extrait avec la résine Sphérosil "QMA" et à $35 \%$ pour le concentré obtenu avec la résine Sphérosil «S" (De Wit et al., 1983).

Une technique analogue au procédé Sphérosil "S" consiste à introduire le lactosérum à $\mathrm{pH} 3$ sur la colonne échangeuse d'ions. Après lavage à l'eau du matériel non adsorbé, les protéines sont détachées par un lavage à $\mathrm{pH}$ 8-9, concentrées par ultrafiltration puis séchées par atomisation. Le produit résultant est dénommé «Bipro Dairy Albumen". II contient $97 \%$ de protéines et seulement quelques traces de matière grasse et de lactose (Anonyme, 1982).

Un autre procédé, le procédé "Vistec", utilise la sulfopropylcellulose comme résine échangeuse de cations et l'adsorption des protéines a lieu dans un réacteur à agitation mécanique. Le rendement de la purification protéique après séparation du complexe résine-protéine du lactosérum déprotéiné, élution des protéines à $\mathrm{pH} 9$ et concentration par ultrafiltration est de $85 \%$ et les concentrés obtenus après séchage contiennent jusqu'à $95 \%$ de protéines (Matthews, 1984).

L'avantage principal de ces concentrés protéiques, comparé aux concentrés protéiques obtenus par ultrafiltration sans clarification thermocalcique préalable, est la quasi-absence de lipides résiduels et d'agents oxydants (fer, cuivre). Leurs propriétés fonctionnelles et leur conservation sont supérieures, en raison de l'absence de développement de saveurs indésirables. De plus, aux concentrations protéiques très élevées, le procédé par échange d'ions est supérieur à l'ultrafiltration d'un point de vue économique (Mirabel, 1981). Ces protéines possèdent d'excellentes propriétés moussantes, gélifiantes, émulsifiantes et de rétention d'eau, si bien qu'elles sont utilisées en boulangerie (pâtes riches en protéines), pâtisserie (pâte à tarte, meringue, crème pâtissière, garnitures fouettées, biscuits), confiserie, crème glacée et charcuterie. La quasi-absence de matières grasses, minéraux et lactose permet également d'utiliser ces protéines en complément ou en remplacement d'autres types de protéines (caséinates, isolats de soja) et surtout le blanc d'œuf, puisque ces concentrés semblent être les ingrédients laitiers possédant les propriétés fonctionnelles les plus proches de celles de l'œuf. En raison de leur très haute valeur nutritionnelle, ces isolats peuvent être utilisés dans les produits diététiques (suppléments protéiques pour sportifs, fortification protéique des boissons).

\section{Concentrés obtenus par chromatogra- phie d'affinité}

Al-Mashikhi et al. (1988) ont montré qu'il est possible, par chromatographie d'adsorption et d'affinité, en utilisant le cuivre comme chélatant, de séparer les immunoglobulines, la lactoferrine et la lactoperoxydase de l' $\alpha$-lactalbumine et de la $\beta$ lactoglobuline. En raison de la possibilité d'utiliser cette technique à grande échelle, les auteurs proposent de purifier ces protéines par chromatographie d'affinité et de les incorporer aux formules pour nourrissons. 


\section{Concentrés obtenus par filtration sur gel}

La filtration sur gel consiste à séparer les molécules selon leur taille. En général, un lactosérum concentré à $20 \%$ de solides, centrifugé, filtré et appliqué sur une colonne contenant un gel Sephadex G 75 ou G 100 est séparé en deux fractions. La première contient les protéines, qui n'ont pu pénétrer le gel en raison de leur taille, et la seconde le lactose et les minéraux. Après concentration et séchage, le produit final contient 30 à $80 \%$ de protéines (Marshall, 1982). Holsinger et al. (1973) ont montré qu'un traitement couplé d'ultrafiltration et de filtration sur gel permet d'obtenir après séchage un produit contenant $81,5 \%$ de protéines, $10 \%$ de lactose et $1,5 \%$ de cendres. Des boissons fortifiées par $1 \%$ de ces concentrés protéiques se sont conservées un an sans changement majeur. Forsum et al. (1974) ont réussi à séparer, par filtration sur gel, les protéines du lactosérum en 3 fractions. La première contient la sérum albumine, la $\beta$-lactoglobuline les résidus de caséine; la seconde fraction contient de la $\beta$-lactoglobuline très pure et la troisième fraction l' $\alpha$-lactalbumine contaminée par la $\beta$-lactoglobuline. Delaney (1980) rapporte que du lactosérum frais est traité industriellement en couplant la filtration sur gel et la centrifugation, d'après la technique mise au point par Moor et al. (1967). Cette technique consiste à déposer l'échantillon à la surface du gel placé à l'intérieur d'un panier en rotation à $60 \mathrm{~g}$. Après $5 \mathrm{~min}$, la force de centrifugation est augmentée à $1000 \mathrm{~g}$ pendant 10 à $15 \mathrm{~min}$ et les protéines sont exclues du gel. Par la suite, le lactose et les substances de faible poids moléculaire sont élués par 2 volumes d'eau pendant $10-15 \mathrm{~min}$ à $60 \mathrm{~g}$. L'avantage de la technique par rapport à la filtration sur gel en colonne est de traiter des volumes supérieurs, plus rapidement et avec une dilution minimale de la fraction protéique. Le lactosérum est séparé en lactose et en 3 types de fractions protéiques. Les poudres possèdent 86 à $95 \%$ de solubilité entre $\mathrm{pH} 3,5$ et 8,0 . Ces poudres sont utilisées dans les aliments pour enfants et en milieu hospitalier.

En ce qui concerne les propriétés fonctionnelles, un traitement thermique de $60^{\circ} \mathrm{C}, 30$ min à pH 7, améliore les propriétés moussantes des concentrés obtenus par filtration sur gel (Richert et al., 1974) ainsi que le volume spécifique et la stabilité de la mousse (Hansen \& Black, 1972).

Malgré de grands espoirs fondés sur cette technique au début des années 70 , ce procédé est très peu utilisé industriellement. En effet, il est coûteux, son rendement est faible $(65 \%)$, la concentration protéique de l'éluat est très faible, les problèmes de colmatage (protéines, phosphate de calcium, lipides), de nettoyage et de contrôle de la croissance microbienne sont nombreux (Matthews, 1984; Marshall, 1982).

\section{Concentrés obtenus par précipitation par les polyélectrolytes}

La précipitation par les polyélectrolytes permet d'obtenir des concentrés de protéines (généralement de protéines de lactosérum) peu ou pas dénaturées, tout en offrant une alternative à d'autres procédés, comme l'ultrafiltration ou la chromatographie, plus délicats et plus coûteux. Les agents précipitants sont nombreux et disparates, il peut s'agir de sels, de polymères ou de solvants. Ces agents lient les protéines par des interactions électrostatiques et l'ensemble précipite sous forme d'agrégats macromoléculaires à un certains $\mathrm{pH}$. Mentionnons que la carboxyméthylcellulose est l'agent précipitant le plus couramment utilisé, en raison de la faible teneur en cendres du concentré. En revanche, avec d'autres agents précipitants, une teneur en cendres élevée (12 à 
$28 \%$ ) dans les concentrés obtenus présente des inconvénients. II est cependant possible, au niveau du laboratoire, de dessaler le produit par action d'hydrosulfite de sodium à $\mathrm{pH} 2$, suivi d'un passage sur un gel Sephadex G 25 (Mathur \& Shahani, 1979). Les concentrés protéiques obtenus sont riches en protéines (60 à $90 \%$ ). Du fait de la non-dénaturation, les protéines ont conservé leurs propriétés nutritionnelles et fonctionnelles. Les propriétés moussantes et gélifiantes sont voisines de celles du blanc d'œuf (Sternberg et al., 1976). En revanche, d'après Morr (1979a), la faible solubilité à $\mathrm{pH}$ acide $(4,6-5,0)$ et la viscosité excessive des concentrés de protéines de lactosérum, obtenus par précipitation au metaphosphate et à la carboxyméthylcellulose, limite leur utilisation aux produits structurés.

\section{Concentrés de protéines de lactosé- rum à lactose hydrolysé}

Des CPL dont le lactose a été hydrolysé en glucose et galactose sont maintenant produits commercialement. Ils sont surtout utilisés pour réduire la cristallisation du lactose, pour atténuer les effets de l'intolérance au lactose. Ils pourraient également être utilisés comme agents édulcorants et stabilisants dans les desserts congelés, comme additifs nutritifs ou agents de brunissement dans le pain ou encore pour allonger le temps de conservation des CPL et éviter leur séchage (Modler, 1985b).

\section{Propriétés et utilisations des CPL}

II est possible, par chauffage pendant 16 à $20 \mathrm{sec}$ à $80^{\circ} \mathrm{C}$ d'un CPL à $18 \%$ de protéines ajusté à $\mathrm{pH} 7,7$, d'obtenir après séchage un produit qui possède des propriétés gélitiantes lorsqu'il est reconstitué et chauffé (Herz, 1982). Un CPL contenant $60 \%$ de protéines chauffé à 80 - $100^{\circ} \mathrm{C}$ pendant 10 à 30 min possède l'apparence et la consistance du blanc d'œuf dur (Chang \& Scibelli, 1982). D'une manière générale, chauffées à $70-85^{\circ} \mathrm{C}$ et à une concentration supérieure à $5 \%$, les protéines du lactosérum forment un gel thermoirréversible, en raison de la formation de liaisons disulfures intermoléculaires au cours de l'étape d'agrégation. En mélange avec du lait écrémé (teneur protéique de $1,5 \%$ ), soit la moitié de la teneur requise pour le blanc d'œuf, un gel peut être obtenu après chauffage pendant 5 min à $85^{\circ} \mathrm{C}$ (McDonough et al., 1974). Les CPL sont renommés pour leurs propriétés moussantes. La capacité moussante est d'autant plus élevée que la charge nette des protéines est élevée et la stabilité augmente lorsque le $\mathrm{pH}$ est supérieur à 6 (Kuelher et Stine, 1974). En raison de leur aptitude à la gélification et au moussage, de nombreuses tentatives de substitution des œufs par les CPL ont été réalisées. En pâtisserie, outre la possibilité d'obtenir des meringues d'apparence identique à celles obtenues à l'aide du blanc d'œuf (De Boer et al., 1977; De Wit et al., 1983), le remplacement de 50 à $100 \%$ du jaune d'œuf ou de l'œuf entier par les CPL est possible suivant le type de produit, à condition de modifier légèrement la recette et les conditions de cuisson (Cocup \& Sanderson, 1987). La couleur et la texture obtenues sont très acceptables, cependant la saveur typique conférée par l'œuf fait défaut (De Wit et Hontelez-Backx, 1981).

Les CPL sont utilisés en boulangeire pour l'apport protéique, la rétention d'eau, la texture, le brunissement du pain, le rehaussement de la saveur et de la valeur nutritionnelle, mais ils réduisent le volume de la pâte. Cependant, la dénaturation thermique en présence de bromate améliore la levée de la pâte (Modler, 1985b). II est possible d'ajouter à la farine $6 \%$ de CPL et d'obtenir du pain au goût tout à fait 
acceptable, qui pourrait être consommé par les populations souffrant de malnutrition (Renz-Schauen \& Renner, 1987).

Les propriétés gélifiantes, épaississantes, émulsifiantes et de rétention d'eau des CPL sont exploitées dans les produits carnés (Moor, 1985; Sanderson, 1988c). A faible concentration dans le surimi, ils peuvent améliorer la force du gel (Sanderson, 1988c).

En raison de leur solubilité à $\mathrm{pH}$ acide (Morr, 1985), les CPL peuvent être utilisés jusqu'à concurrence de $3 \%$ pour fortifier les boissons et les jus de fruits en protéines. Le produit reste clair et stable à condition d'avoir été préalablement clarifié (De Boer et al., 1977).

En raison de leur valeur nutritionnelle, les CPL et les CPL à lactose hydrolysé sont utilisés dans les formules pour enfants et comme suppléments protéique dans les produits diététiques et pharmaceutiques (Morr, 1985; Modler, 1985b).

En association avec le caséinate de sodium, les CPL contribuent à la formation d'une émulsion stable, lient l'eau et créent la texture et la tartinabilité souhaitées dans les beurres et pâtes à tartiner "légers" (Kjaergaard Jensen et al., 1987).

Les CPL peuvent être utilisés comme agents liants dans des aliments contenant un mélange de protéines texturées (voir protéines texturées).

\section{Les coprécipités}

Les coprécipités sont obtenus losqu'un traitement thermique sévère $\left(90^{\circ} \mathrm{C}\right)$ est appliqué au lait écrémé. II se forme alors un complexe entre les protéines du lactosérum dénaturées et les caséines, par l'intermédiaire de liaisons disulfures. Une acidification à $\mathrm{pH} 4,6$ et l'addition de chlorure de calcium permet de précipiter le complexe protéique et de récupérer environ $96 \%$ des protéines. La teneur moyenne en protéines est de $83 \%$. En jouant sur la quantité de calcium ajoutée $(3,0-0,5 \%)$, le $\mathrm{pH}(5,8$ à 4,6$)$ et la durée du traitement thermique (1 à $20 \mathrm{~min}$ ) il est possible d'obtenir différentes qualités de coprécipités (Muller, 1982). Les coprécipités à teneur élevée en calcium possèdent les meilleures qualités organoleptiques au cours de la conservation, alors que des saveurs indésirables peuvent se développer chez les autres types de coprécipités.

La formation de coprécipités se fait au détriment de la solubilité (particulièrement à $\mathrm{pH} 6,7-7,2)$, puisque 4 à $15 \%$ des protéines du lactosérum sont dénaturées. Cependant, la solubilité peut être améliorée par des agents séquestrants du calcium, afin d'augmenter la dispersibilité (Southward \& Goldman, 1975), ou par une série d'étapes d'ajustements du $\mathrm{pH}$ et de chauffage, refroidissement. II en résulte un produit soluble à $95 \%$ (Modler \& Jones, 1987). Le pouvoir émulsifiant des coprécipités à teneur élevée en calcium est supérieur à celui des autres précipités et à celui du caséinate de sodium (Southward \& Goldman, 1978). L'aptitude au fouettage des coprécipités est inférieure à celle de l'albumine de l'œuf, mais supérieure à celle du caséinate de sodium (Modler, 1985a).

Les coprécipités solubles sont utilisés dans les produits à teneur en eau élevée ou intermédiaire. En chocolaterie, ils contribuent à la stabilité de la saveur et aux propriétés antioxydantes. La bonne stabilité à la chaleur des coprécipités permet de les incorporer aux produits UHT, aux yoghourts, aux crèmes fouettées et aux produits tartinables à teneur réduite en matière grasse. Les coprécipités peu solubles peuvent également contribuer à la texture des céréales de petit-déjeuner, des produits de boulangerie, des pâtes alimentaires ainsi qu'au rehaussement de 
la valeur nutritionnelle (Modler, 1985a; Morr, 1985). Ils sont utilisés en charcuterie-salaisonnerie pour leur aptitude à lier l'eau et la matière grasse (Morr, 1982).

En raison de la présence des protéines du lactosérum riches en lysine, tryptophane et en acides aminés soufrés, les coprécipités possèdent une valeur nutritionnelle supérieure à celle des caséines et présentent un intérêt certain dans les formules destinées aux nourrissons et aux individus intolérants au lactose (Jonas, 1973).

\section{Les protéines totales du lait}

Les protéines totales du lait sont un nouveau type d'ingrédient préparé par ajustement du $\mathrm{pH}$ à 10 , chauffage à environ $70^{\circ} \mathrm{C}$ pour solubiliser les micelles de caséine, acidification à $\mathrm{pH} 3,5$ pour complexer les caséines et les protéines du lactosérum, ajustement du $\mathrm{pH}$ à 4,6 pour précipiter les protéines complexées, lavage et séchage. Bien que de composition sensiblement identique à celle des coprécipités, les préparations de protéines totales ont une très bonne solubilité et les protéines du lactosérum non dénaturées ont conservé leurs propriétés fonctionnelles intactes (Morr, 1985). Ce type d'ingrédient peut être utilisé pour sa qualité nutritionnelle et ses propriétés émulsifiantes, moussantes et de rétention d'eau dans les aliments diététiques, les produits carnés et les garnitures fouettées (Sanderson, 1988b). En association avec de faibles concentrations de CPL dans le surimi, la texture et la résistance du gel sont améliorées (Sanderson, 1988c).

\section{Les protéines texturées}

Des isolats de protéines laitières, contenant au moins $90 \%$ de protéines, peuvent être texturés par filage. Des dispersions de protéines laitières sont pompées sous pression à travers un orifice et coagulées dans une solution d'acide acétique et de $\mathrm{NaCl}$ (Jaynes \& Asan, 1976). Suite à leur réorientation et à leur élongation parallèle, les protéines vont s'associer entre elles par des liaisons hydrogène et disulfure pour former une fibre. L'extrusion thermoplastique permet également de texturer les protéines laitières. Des concentrés protéiques sont soumis à une température, une pression et des forces de cisaillement très élevées. Après extrusion et refroidissement, le produit a l'aspect de granules dont la structure est fortement expansée.

Maga \& Kim (1986) ont étudié l'extrusion de mélanges de lactosérum doux séché ou de CPL avec du riz, des tomates, du maïs, de la farine de blé ou

du blé entier. Ils ont montré qu'il est possible d'incorporer jusqu'à $20 \%$ de lactosérum sans altérer l'expansion du produit, sa consistance et sa couleur. Des dégustateurs ont préféré un produit formé de 10 à $20 \%$ de CPL extrudés avec de la farine de riz à un témoin sans CPL (Kim \& Maga, 1987). Des fibres protéiques préparées à partir de concentrés protéiques de lactosérum peuvent être utilisées dans les produits carnés. II est possible de remplacer $20 \%$ de la viande de saucisse par des caséines texturées (Poznanski et al., 1982). La coextrusion de la caséine (10$30 \%$ ) et de la farine de blé n'a pas d'effet négatif sur les propriétés physiques et 
organoleptiques et peut trouver des applications en boulangerie (Van de Voort et al., 1984). D'une manière générale, l'extrusion est un procédé assez coûteux et peu répandu. Les éventuelles applications se trouvent au niveau de la production d'ingrédients dérivés de protéines de lait écrémé texturées pouvant être incorporés dans la viande hachée (English, 1981).

\section{MODIFICATION DES PROPRIÉTÉS FONCTIONNELLES DES PROTÉINES LAITIERES PAR TRAITEMENT PHY- SIQUE, CHIMIQUE OU ENZYMATIQUE}

Nous avons vu précédemment qu'il est possible d'obtenir, à partir de lait écrémé ou de lactosérum, une gamme d'ingrédients alimentaires aux propriétés fonctionnelles distinctes et spécifiques favorisant leur incorporation dans tel ou tel aliment. L'application de traitements physiques, chimiques ou enzymatiques aux ingrédients existants permet d'améliorer certaines de leurs propriétés fonctionnelles et d'étendre leur utilisation.

\section{Modifications physiques par traite- ments thermiques}

Une dénaturation partielle consécutive à un traitement thermique conduit à un déroulement de la protéine et à un démasquage des groupements hydrophobes qui peuvent s'orienter à l'interface air-eau ou huile-eau, ce qui confère un caractère plus amphipolaire à la molécule et permet d'améliorer les propriétés d'agent surfactant et de rétention d'eau (Cheftel \& Lorient, 1982; Modler, 1985b). Un traitement thermique appliqué à un
CPL peut multiplier par 2 l'absorption d'eau, en raison de la formation d'un réseau protéique gélifié qui serait capable, après séchage, d'absorber l'eau par capillarité (Cheftel \& Lorient, 1982).

Un traitement de chaleur à $55-65^{\circ} \mathrm{C}$ appliqué aux CPL améliore la solubilité (Nakai \& Li-Chan, 1985) et facilite l'orientation des protéines du lactosérum à l'interface air-eau (Richert et al., 1974). Entre 40 et $65^{\circ} \mathrm{C}$, à $\mathrm{pH}$ neutre ou légèrement alcalin, le traitement de chaleur a un effet positif sur le pouvoir moussant des protéines du lactosérum (Richert et al., 1974; Paquet et al., 1978; De Wit \& Klarenbeek, 1984). Des traitements de chaleur de l'ordre de $70^{\circ} \mathrm{C}$ appliqués aux protéines du lactosérum affectent particulièrement la solubilité, le pouvoir moussant et émulsifiant, qui commencent à décroître alors que l'absorption d'eau et la viscosité augmentent (De Wit \& De Boer, 1975b). La plupart des auteurs admettent que certaines propriétés fonctionnelles, comme le pouvoir émulsifiant et moussant, sont directement corrélées avec la solubilité. De Wit et De Boer (1975b) affirment que la stabilité d'une émulsion préparée à l'aide d'un CPL ayant subi un traitement thermique est d'autant plus faible que le traitement thermique est sévère et que la solubilité est abaissée. Cependant, Chobert et al. (1988) ont montré que l'amélioration de la solubilité des protéines au point isoélectrique n'est pas accompagnée d'une amélioration de la capacité émulsifiante et que les protéines les plus solubles ne sont pas celles qui possèdent la capacité émulsifiante la plus élevée.

\section{Modifications chimiques}

On appelle modification chimique la substitution ou l'addition de groupements aux 
protéines par liaison covalente, hydrophobe ou ionique.

\section{Acétylation et succinylation}

Les groupements $\alpha$ et $\varepsilon$-aminés dont la charge est fortement positive au $\mathrm{pH}$ des aliments sont transformés en groupements anioniques porteurs de charges négatives (succinylation) ou nulle (acétylation). La modification des répulsions électrostatiques par création de charges négatives (succinylation) et réduction des charges positives (acétylation) résulte en un étirement ou un déplissement des protéines, d'où une réduction des tensions de surface huile-eau et air-eau.

L'acétylation augmente la solubilité de la caséine à $\mathrm{pH}$ acide (Fox \& Mulvihill, 1983; Girerd et al., 1984) ainsi que le pouvoir hydratant des protéines du lactosérum (Anonyme, 1984) et la stabilité à la chaleur de la caséine (Craemer et al., 1971). La succinylation des protéines de lactosérum précipitées au point isoélectrique améliore toutes les propriétés fonctionnelles, à l'exception du moussage (Cheftel \& Lorient, 1982; Thompson \& Reyes, 1980; Fox et al., 1982; Girerd et al., 1984).

En boulangerie, l'emploi de concentrés de protéines de lactosérum succinylées diminue le temps de levée de la pâte (Thompson \& Baker, 1983). Les CPL succinylés peuvent remplacer $20 \%$ du caséinate de sodium dans les imitations de crème à café et $20 \%$ du jaune d'œu dans les sauces à salade (stabilité de l'émulsion et viscosité supérieures) (Thompson \& Reniers, 1982). Ils peuvent également être utilisés comme agents liants dans les croquettes à base de viande (Thompson et al.,1982).

Malgré l'hydrolyse in vivo des liaisons covalentes dans lesquelles sont impliqués des groupements $\varepsilon-\mathrm{NH}_{2}$ d'acides aminés essentiels tels que la lysine (Puigserver et al., 1979), les produits obtenues à l'aide de ces méthodes ont la réputation de posséder une faible qualité nutritionnelle et leur utilisation se heurte à la législation (Cheftel \& Lorient, 1982).

\section{Estérification}

L'estérification des protéines consiste à transformer les charges négatives des groupements carboxyles à $\mathrm{pH}$ neutre en charges positives. La charge nette de la protéine devient alors positive. L'estérification est réalisée en milieu acide par l'alcool éthylique ou méthylique. L'avantage de l'estérification est d'agir au niveau d'acides aminés non essentiels, comme l'acide aspartique et l'acide glutamique.

L'estérification des protéines du lactosérum augmente l'hydrophobicité et le pouvoir gélifiant (Olson, 1982). Dans le cas de l'estérification de la $\beta$-lactoglobuline (Mattarella et al., 1983, Mattarella \& Richardson, 1983), l'activité émulsifiante est légèrement inférieure à celle de la protéine native, cependant la stabilité de l'émulsion est augmentée significativement, ce qui en fait un ingrédient pouvant améliorer la stabilité des émulsions dans les produits alimentaires.

\section{Phosphorylation}

Comme dans le cas de la succinylation, la phosphorylation crée de nouvelles répulsions électrostatiques à l'intérieur de la chaîne polypeptidique, par l'augmentation du nombre de groupements hydrophiles anioniques. La phosphorylation chimique est obtenue par attachement covalent à la protéine d'atomes de phosphore provenant d'oxychlorure de phosphore. II peut également se créer des liaisons internes par l'intermédiaire de ponts phosphates (Kester \& Richardson, 1984). D'après Girerd et al. (1984), la phosphorylation de 
la caséine augmente le pouvoir moussant et émulsifiant ainsi que sa solubilité à tous les $\mathrm{pH}$, particulièrement lorsque la caséine est hautement phosphorylée. D'après Matheis et al. (1983), l'addition de 7,4 groupes phosphates par mole de caséine améliore la viscosité et la rétention d'eau, mais diminue légèrement la solubilité et la capacité émulsifiante. La phosphorylation de la $\beta$-lactoglobuline augmente la dispersibilité, la capacité émulsifiante et gélifiante (Olson, 1982), la stabilité de l'émulsion et la viscosité (Woo \& Richardson, 1983). Les propriétés de la $\beta$-lactoglobuline phosphorylée rendent possible l'utilisation des protéines du lactosérum dans les sauces et les mayonnaises qui requièrent des ingrédients possédant de bonnes propriétés émulsifiantes (Kester \& Richardson, 1984).

\section{Hydrolyse chimique}

La plupart des protéines sont complètements hydrolysées en leurs acides aminés constitutifs par chauffage à $110^{\circ} \mathrm{C}$ pendant 20 à $70 \mathrm{~h}$ en milieu acide (hydrolyse acide) ou alcalin (hydrolyse alcaline). Le mélange d'acides aminés libres obtenus peut être instillé par voie parentérale et entérale à des patients souffrant d'insuffisance digestive. Cependant, les effets secondaires de ce type d'hydrolyse sont nombreux. Dans le cas de l'hydrolyse acide, il y a destruction complète du tryptophane et destruction en quantités variables de la sérine et de la thréonine, désamination de la glutamine et de l'asparagine, déshydratation intramoléculaire de certains acides aminés donnant naissance à des anhydrides cycliques. Dans le cas de l'hydrolyse alcaline, le tryptophane n'est pas détruit, cependant il y a perte de la sérine, de la thréonine, de l'arginine et de la cystéine, tous les acides aminés sont racémisés et il existe des risques de formation de composés indésirables (lysino-alanine, ornitho-alanine, isopeptides).

\section{Hydrolyse enzymatique}

En dehors de l'utilisation de la présure en fabrication fromagère et pour la production de caséine, l'hydrolyse enzymatique des protéines laitières permet de modifier leurs propriétés fonctionnelles et nutritionnelles. Au contraire de l'hydrolyse chimique, les conditions d'hydrolyse $(\mathrm{pH}$, température, force ionique) sont modérées et la qualité nutritionnelle est préservée.

Jost et al. (1982) ont mis en évidence que la baisse de tension de surface provoquée par les hydrolysats trypsiques et chymotrypsiques de CPL (5 à 7 résidus aminés) est plus forte que la baisse de tension de surface due aux protéines non hydrolysées. En revanche, la baisse de tension de surface occasionnée par les peptides comprenant 3 à 4 résidus aminés est inférieure à celle des protéines non hydrolysées. Ces résultats montrent l'importance du contrôle de la réaction d'hydrolyse, de manière à modifier positivement les propriétés fonctionnelles des protéines. De plus, cela limite les risques d'apparition d'amertume. D'après Kuelher et Stine (1974), l'accroissement de la quantité de peptides résultant de l'hydrolyse enzymatique permet d'augmenter la quantité d'air emprisonnée ou la quantité d'huile pouvant être émulsifiée. En revanche, si l'hydrolyse est trop poussée, les peptides ont une taille moyenne trop réduite pour pouvoir stabiliser convenablement les mousses et les émuisions.

En ce qui concerne les propriétés fonctionnelles, les auteurs s'entendent sur le fait que l'hydrolyse enzymatique améliore la solubilité des caséines au point isoélectrique et des protéines du lactosérum dénaturées (Monti \& Jost, 1978; Saint Paul et al., 1984; Chobert et al., 1988). Cette propriété permet de fortifier en protéines les jus de fruits et autres aliments acides par les hydrolysats de protéines 
laitières (Holsinger et al., 1973; Helbig et al., 1980; Fox et al., 1982; Ma et al., 1983).

En revanche, en ce qui concerne d'autres propriétés fonctionnelles, comme les pouvoirs moussant, émulsifiant et gélifiant, les résultats sont parfois contradictoires. D'après Paquet et al. (1978), I'hydrolyse des protéines du lactosérum améliore la stabilité de la mousse. To et al. (1985) ont montré que le traitement d'un CPL par la pepsine et la cystéine permet d'obtenir une capacité moussante et gélifiante identique à celle du blanc d'œuf séché par atomisation, sans qu'on observe de chute de la stabilité de la mousse. D'après Kuelher \& Stine (1974), l'hydrolyse limitée des protéines du lactosérum par la pronase, la prolase ou la pepsine diminue la capacité émulsifiante, augmente le volume spécifique de la mousse, mais diminue la stabilité de celle-ci. De façon similaire, l'hydrolyse de la caséine par la pancréatine augmente le foisonnement de la caséine au détriment de la capacité émulsifiante (Fox \& Mulvihill, 1983). Chobert et al. (1988) ont montré que l'hydrolyse limitée par la trypsine améliore la capacité émulsifiante des caséines au point isoélectrique et des protéines du lactosérum à $\mathrm{pH}$ alcalin. Shimizu et al. (1984) ont démontré que l'extrémité $\mathrm{N}$-terminale de la caséine $\alpha_{51}$ obtenue par hydrolyse enzymatique possède d'excellentes propriétés émulsifiantes. D'après Jost et al. (1982), qui ont testé l'hydrolyse de CPL par 11 préparations enzymatiques différentes, seul l'hydrolysat trypsique confère à l'émulsion une stabilité supérieure à celle du CPL non hydrolysé. Les mêmes auteurs supposent que les peptides issus de l'hydrolyse par la trypsine possèdent des résidus arginine ou lysine, en position C-terminale, dont la structure serait sensiblement analogue à celle du groupement phosphatidyl-choline d'un émulsifiant comme la lécithine. Hidalgo et Gamper (1977) ont montré que l'hydrolyse enzymatique limitée d'un concentré de protéines de lactosérum par la trypsine améliore nettement sa stabilité à la chaleur, sans affecter les propriétés fonctionnelles ni créer de saveurs indésirables.

Au niveau nutritionnel et thérapeutique, l'hydrolyse enzymatique permet de réduire l'allergénicité des protéines sériques, si bien que ce type d'hydrolysat peut servir de source protéique dans les formules pour nourrissons allergiques aux protéines laitières (Jost et al., 1987; Asselin et al., 1988). Dans le cas de patients souffrant d'une insuffisance digestive, des hydrolysats de protéines laitières (généralement de protéines de lactosérum) peuvent constituer l'essentiel de l'apport protéique (Roger et al., 1981; Mendy, 1984; Brockbank, 1984). Ces hydrolysats sont produits industriellement en réacteur enzymatique à membrane. Après avoir été incorporés dans une formule, ils sont utilisés comme aliments de réanimation en milieu hospitalier.

Du point de vue physiologique, les hydrolysats de protéines de lactosérum ont la propriété de stimuler la croissance de la régénération de la peau (Wenner, 1982). Les hydrolysats de protéines laitières pourraient avoir de l'avenir dans le domaine de la cosmétologie. Encapsulés à l'intérieur de liposomes, ils pourraient accélérer la régénération des cellules de la peau et retarder son vieillissement. Enfin, la production de peptides à activité biologique par hydrolyse de protéines laitières est actuellement en plein développement. II peut s'agir des phosphopeptides contenus dans les caséines qui jouent un rôle dans l'absorption des minéraux (Brulé et al., 1980). La séquence 6066 de la $\beta$-caséine est comparable à celle de médiateurs ayant un rôle analogue à celui de la morphine et jouant un rôle au niveau de la régulation de l'appétit et du 
sommeil (Mendy, 1984; Maubois, 1984). Meisel \& Frister (1988) ont isolé le fragment $60-70$ de la caséine bovine, nommé $\beta$-casomorphine, qui possède une activité d'opiacé et affecte la sécrétion d'insuline et de somatostatine. Ils ont également identifié un caséinophosphopeptide (séquence 66-74 de la caséine $\alpha_{\text {s1 }}$ ) qui augmente l'absorption du calcium au niveau de l'intestin. D'après Migliore-Samour et al. (1988), les peptides issus de la digestion enzymatique des caséines humaines (séquence 54-59) et bovines (séquence 63-68) stimulent le système immunitaire du nouveau-né. Azuma et al. (1988) ont isolé 3 peptides (séquences $1-18$ et 105117 de la caséine $\beta$ humaine, séquence 177-183 de la caséine $\beta$ bovine) ayant une activité stimulant la DNA synthétase. L'hexapeptide en position C-terminale de la caséine $\alpha_{\mathrm{s} 1}$ a une activité inhibitrice envers l'enzyme convertisseur de l'angiotensine I en angiotensine II, qui est un vasoconstricteur très puissant (Maruyama et al., 1987). La séquence 177-183 de la caséine $\beta$ aurait le même effet (Maubois \& Léonil, 1988). Bien que la plupart des peptides à activité exorphique ou immunostimulante aient été localisés dans les caséines et plus particulièrement dans la séquence $60-70$ de la caséine $\beta$, il faut s'attendre à trouver des peptides ayant la même action chez les protéines du lactosérum et plus particulièrement chez l' $\alpha$ lactalbumine. L' $\alpha$-lactalbumine est la protéine laitière la plus riche en tryptophane, que l'on retrouve chez le précurseur de la sérotonine et dans les peptides à activité opioïde (Maubois \& Léonil, 1988).

\section{CONCLUSION}

Certaines techniques disponibles pour modifier les propriétés fonctionnelles des protéines laitières, telles la phosphorylation enzymatique, la déphosphorylation, l'hydroxylation, la lipophilisation, le crosslinking, la réaction de plastéine, le greffage d'acides aminés, d'hydrates de carbone et de groupes sulfhydriles, ont été volontairement passées sous silence car n'ayant pas dépassé le stade du laboratoire.

Les traitements chimiques permettent de modifier considérablement les propriétés fonctionnelles des protéines. Cependant, les doutes relatifs à leur effet négatif au niveau de la valeur nutritionnelle ainsi qu'à la présence de résidus de l'agent chimique limitent l'utilisation des protéines modifiées chimiquement, à moins de démontrer l'inocuité du produit par une tude nutritionnelle et toxicologique sérieuse. De telles investigations sont néanmoins très utilles pour élucider l'effet de la charge nette de la protéine sur sa conformation et ses propriétés fonctionnelles.

Le développement des traitements physiques de concentration et de séparation des protéines laitières permet d'obtenir à l'échelle industrielle des fractions protéiques enrichies, relativement pures, aux propriétés fonctionnelles spécifiques. De plus, la valeur nutritionnelle élevée des ingrédients laitiers vis à vis des protéines végétales est déterminante quant au choix de l'ingrédient. Dans certains cas, l'emploi simultané d'ingrédients protéiques d'origine laitière en combinaison avec les protéines végétales est recherché, afin d'obtenir un produit possédant les caractéristiques fonctionnelles et nutritionnelles désirées. Dans ce domaine, les recherches sont très actives, car ces mélanges possèdent souvent des caractéristiques fonctionnelles que chaque ingrédient ne possède pas individuellement. La transformation des protéines laitières en une gamme d'ingrédients ali- 
mentaires permet donc de valoriser une partie des excédents de protéines, de répondre aux besoins de l'industrie alimentaire en ingrédients aux propriétés fonctionnelles spécifiques et de faire face à la concurrence des autres sources d'ingrédients protéiques. A ce sujet, bien que peu de protéines alimentaires soient aussi bien connues que celles du lait, que leur valeur nutritionnelle soit excellente et qu'il soit possible de produire une gamme importante de dérivés aux propriétés spécifiques, la compétition face à l'industrie des protéines végétales est rude et a tourné à l'avantage de cette dernière pour bien des ingrédients. II est donc primordial pour l'industrie laitière de pouvoir proposer des ingrédients aux caractéristiques fonctionnelles inégalables par les compétiteurs, afin de redevenir le fournisseur principal d'ingrédients à l'industrie alimentaire (Sanderson, 1988b). Ceci devrait être possible grâce aux techniques actuelles, permettant de séparer et d'obtenir sous des conditions modérées des isolats protéiques aux propriétés fonctionnelles intactes ou améliorées.

Les résultats obtenus au niveau des propriétés physiologiques de certaines séquences des caséines et la possibilité infinie de générer de nouvelles séquences par hydrolyse enzymatique laissent entrevoir d'importants développements dans le domaine du fractionnement et de la caractérisation fine des hydrolysats de protéines laitières. De nouveaux marchés à très forte valeur ajoutée (parapharmaceutique, cosmétique) deviendraient ainsi accessibles aux ingrédients laitiers. Nous avons vu qu'il existe de nombreux procédés de fractionnement des protéines du lactosérum. En revanche, le fractionnement à grande échelle des caséines est beaucoup plus difficile, en raison de la plus grande simili- tude de leurs propriétés physico-chimiques. Cependant, certaines études de fractionnement des caséines se font actuellement au stade pilote. II est en effet possible de dissocier les micelles à froid et de produire, par microfiltration tangentielle, de la caséine $\beta$ pure à $90 \%$ (Maubois \& Léonil, 1988).

Afin de tirer le meilleur parti des protéines laitières comme ingrédient, il serait à l'avenir souhaitable de standardiser les méthodes d'évaluation des propriétés fonctionnelles et de développer des systèmes modèles permettant d'étudier les interactions complexes des ingrédients laitiers en présence d'autres constituants.

\section{REMERCIEMENTS}

Ce travail a été réalisé grâce au soutien du ministère de l'Agriculture, des Pêcheries et de I'Alimentation du Québec.

\section{RÉFÉRENCES}

Al-Mashikhi S.A., Li-Chan E. \& Nakai S. (1988) Separation of immunoglobulins and lactoferrin from cheese whey by chelating chromatography. J. Dairy Sci. 71, 1747-1755

Anonyme (1982) Super protein from acid whey. Food Eng. 54, 3, 96-97

Anonyme (1984) Modification of whey and whey components. N.Z. J. Dairy Sci. Technol. 14, 141-142

Asselin J., Amiot J., Gauthier S.F., Mourad W. \& Hebert J. (1988) Immunogenicity and allergenicity of whey protein hydrolysates. J. Food Sci. 53, 1208-1211

Azuma N., Nagaune S.I., Kaminogawa S. \& Yamauchi K. (1988) DNA synthesis stimulating peptides from human and bovine B caseins. Hannah Research Casein Conference, Ayr, Scotland

Bridel (1981) Procédé de fabrication de la caséine. Brevet Fr. $n^{\circ} 2480568$ 
Brockbank R. (1984) Uses for dairy ingredients in dietary and nutritional foods. J. Soc. Dairy Technol. 37, 4, 127-130

Brulé G., Roger L., Fauquant J. \& Piot M. (1980) Procédé de traitement d'une matière à base de caséine contenant des phosphocaséinates de cations monovalents et leurs dérivés. Produits obtenus et applications. Brevet français $n^{\circ} 8002281$

Campbell L.B. \& Pavlasek S.J. (1987) Dairy products as ingredients in chocolate and confections. Food Technol. 41, 10, 78-85

Chang P.K. \& Scibelli G.E. (1982) Use of heat coagulated whey protein concentrate as a substitute for gelled egg white. US Pat. 4, 362, 761

Cheftel J.C. \& Lorient D. (1982) Les propriétés fonctionnelles des protéines laitières et leur amélioration. Lait 62, 435-483

Cheftel J.C., Cuq J.L. \& Lorient D. (1985) Protéines Alimentaires. Lavoisier, Paris, p. 45

Chobert J.M., Bertrand-Harb C. \& Nicolas M.G. (1988) Solubility and emulsifying properties of caseins and whey proteins modified enzymatically by trypsin. J. Agric. Food Chem. 36, 883892

Closs B. \& Lorient D. (1988) Surface properties of whey proteins influencing factors and methods of improvement. Hannah Research Institute Casein Conference, Ayr, Scotland

Cocup R.O. \& Sanderson W.B. (1987) Functionality of dairy ingredients in bakery products. Food Technol. 41, 10, 86-89

Craemer L.K., Roeper J. \& Lohrey E.H. (1971) Preparation and evaluation of some acid soluble casein derivates. N.Z. J. Dairy Sci. Technol. 6, 107-111

Creig R.I.W. (1979) The manufacture properties and use of heat denatured whey protein. Milk Ind. 81, 2, 30-34

De Boer R., De Wit J.N. \& Hiddink J. (1977) Processing of whey by means of membranes and some applications of whey protein concentrate. J. Soc. Dairy Technol. 30, 2, 112-120

De la Guérivière J.F. (1981) Utilisation du lactosérum dans l'alimentation humaine traditionnelle. I. Produits de cuisson céréaliers. Tech. Lait 952, 57-59

De Moor H. \& Huyghebaert A. (1987) Functional properties of dehydrated rich milk products. In : Proceedings of IDF Symposium : Physicochemical Aspects of Dehydrated Protein Rich Milk Products. Holsingor, Denmark, pp. 276301
De Wit J.N. (1981) Structure and functional behaviour of whey proteins. Neth. Milk Dairy J. 35, 47-64

De Wit J.N. \& De Boer R. (1975a) Procédé de clarification de liquides contenant des protéines du petit lait. Brevet néerlandais $n^{\circ} 7513645$

De Wit J.N. \& De Boer R. (1975b) Ultrafiltration of cheese whey and some functional properties of the resulting whey protein concentrate. Neth. Milk Dairy J. 29, 198-211

De Wit J.N. \& Hontelez-Backx E. (1981) Les propriétés fonctionnelles des protéines du lactosérum : conséquences des traitements thermiques. Tech. Lait 952, 19-22

De Wit J.N. \& Klarenbeek G. (1984) Effect of various heat treatments on structure and solubility of whey proteins. J. Dairy Sci. 67,2701 2710

De Wit J.N., Hontelez-Backx E. \& Adamse M. (1988) Evaluation of functional properties of whey protein isolates. 3 . Functional properties in aqueous solution. Neth. Milk Dairy J. 42, 155-172

De Wit J.N., Klarenbeek G. \& Hontelez-Backx E. (1983) Evaluation of functional properties of whey protein concentrates and whey protein isolates. 1. Isolation and characterization. Neth. Milk Dairy J. 37, 37-49

Delaney R.A.M. (1980) Industrial gel filtration of proteins. In : Applied Protein Chemistry (Grant R.A., ed.) Applied Science Publishers, London, pp. $233-280$

Dijkstra W.M. (1988) Le lait dans un monde changeant. Colloque national «Nouvelles utilisations du lait», Québec, Canada

Edwards W.P. (1984) Uses for dairy ingredients in confectionery. J. Soc. Dairy Technol. 37, 4, 122-125

Eigel W.N., Bultler J.N., Ernström C.A., Farrell H.M., Harwalkar V.R., Jenness R. \& McL. Whitney R. (1984) Nomenclature of the proteins of cow's milk : fifth revision. J. Dairy Sci. 67, 1599-1631

English A. (1981) Future uses of skimmed milktexturized processes. J. Soc. Dairy Technol. $34,2,70-73$

Evans E.W. (1986) Interactions of milk components in food systems. In : Interactions of Food Components. (G.G. Birch et M.G. Lindley, eds) Elsevier Applied Science publishers, Londres et New-York, pp. 241-275

Fauquant J., Vieco E., Brulé G. \& Maubois J.L. (1985) Clarification des lactosérums doux par 
agrégation thermocalcique de la matière grasse résiduelle. Lait 65, 1-20

Fil (1987) Method for the determination of the solubility nitrogen index (NSI) and for the determination of the rehydration properties of milk protein products, Oct. (circulaire 88/1)

Forsum E., Hambraeus L. \& Siddiqui 1.H. (1974) Large-scale fractionation of whey protein concentrates. J. Dairy Sci. 57, 659-664

Fox P.F. \& Mulvihill D.M. (1983) Functional properties of caseins, caseinates and casein coprecipitates. In : Proceedings of IDF symposium : Physico-chemical Aspects of Dehydrated Protein-Rich Milk Products, Holsingor, Denmark, pp. 188-259

Fox P.F., Morissey P.A. \& Mulvihill D.M. (1982) Chemical and enzymatic modification of food proteins. In : Developments in Food Proteins. (B.J.F. Hudson, ed.) Applied Science Publishers, Londres et New York, pp. 1-59

Girerd F., Martin J.F., Mesnier D. \& Lorient D. (1984) Influence des modifications chimiques de la caséine sur ses propriétés fonctionnelles. Sci. Aliments 4, hors-série 111, 251-257

Hansen P.M.T. \& Black D.H. (1972) Whipping properties of spray-dried complexes from whey protein and carboxymethyl cellulose. J. Food Sci. 37, 452-456

Harwalkar V.R. \& Emmons D.B. (1969) Low ash albumin as a by-product of lactose production. Can. Inst. Food Sci. Technol. J. 2, 9-11

Helbig N.B., Ho L., Christy G.E. \& Nakai S. (1980) Debittering of skim milk hydrolysates by adsorption for incorporation into acidic beverages. J. Food Sci. 45, 331-335

Herz H.L. (1982) Fabricated food products from textured protein particles. US Pat. 4, 361, 588

Hidalgo J. \& Gamper E. (1977) Solubility and heat stability of whey protein concentrates. $J$. Dairy Sci. 60, 1515-1518

Holsinger V.H., Posati L.P., De Vilbis E.D. \& Pallansch M.J. (1973) Fortifying soft drinks with cheese whey protein. Food technol. 27, 2, 5965

Jaynes H.O. \& Asan T. (1976) Fibrous protein from cottage cheese whey. J. Food Sci. 41, 787-790

Jelen P. \& Schmidt T.S. (1976) Alkaline solubilization of heat precipitated cheese whey proteins. Can. Inst. Food Sci. Technol. J. 9, 61-65

Jonas J.J. (1973) Utilization of dairy ingredients in other foods. J. Milk Food Technol. 36, $6,323-332$
Jost R., Monti J.C., Baechler R. \& Fumeaux D. (1982) Emulgateurs peptidiques obtenus par l'hydrolyse enzymatique partielle de la protéine sérique du lait. Lait 62, 521-530

Jost R., Monti J.C., Pahud J.J. (1987) Whey protein allergenicity and its reduction by technological means. Food Technol. 41, 10, 118121

Kester J.J. \& Richardson T. (1984) Modification of whey proteins to improve functionality. $J$. Dairy Sci. 67, 2757-2774

Kim C.H. \& Maga J.A. (1987) Properties of extruded whey protein concentrates and cereal flour blends. Lebens. Wissens. Technol. 20, 6, $311-318$

Kinsella J.E. (1984) Milk proteins : physicochemical and functional properties. CRC Crit. Rev. Food Sci. Nutr. 21, 197-262

Kinsella J.E. (1987) Physical properties of food and milk components : research needs to expand uses. J. Dairy Sci. 70, 2419-2428

Kitabatake N. \& Doi E. (1982) Surface tension and foaming of protein solutions. J. Food Sci. 47, 1218-1221

Kjaergaard Jensen G., Ipsen R.H. \& Ilsoe C. (1987) Functionality and application of dairy ingredients in dairy products. Food Technol. 41, $10,66-71$

Knipschildt M.E. (1986) Drying of milk and milk products. In : Modern Dairy Technology. Vol. 1. Advances in Milk Processing (R.K. Robinson, ed.) Applied Science Publishers, Londres et New York, pp. 131-234

Kuehler C.A. \& Stine C.M. (1974) Effect of enzymatic hydrolysis on some functional properties of whey protein. J. Food Sci. 39, 379382

Lonergan D.A. (1983) Isolation of casein by ultrafiltration and cryodestabilization. $J$. Food. Sci. $48,1817-1821$

McDermott R.L. (1987) Functionality of dairy ingredients in infant formula and nutritional specialty products. Food Technol. 41, 10, 91-103

McDonough F.E., Hargrove R.E., Mattingly W.A., Posati L.P. \& Alford J.A. (1974) Composition and properties of whey protein concentrates from ultrafiltration. J. Dairy Sci. 57,1438 1443

Ma C.Y., Amantea G.F. \& Nakai S. (1983) Production of nonbitter, desalted milk hydrolysate for fortification of soft drinks and fruit juices. $J$. Food Sci. 48, 897-899 
Maga J.A. \& Kim C.H. (1986) Extrusion of whey/cereal blends. J. Dairy Sci. 69 (suppl. 1) 56

Marshall K.R. (1982) Industrial isolation of milk proteins : whey proteins. In : Development in Dairy Chemistry, 1. Proteins (P.F. Fox, ed.) Applied Science Publishers, Londres et New York, pp. 339-373

Maruyama S., Mitachi J., Awaya J., Kurono M., Tomizuka N. \& Suzuki H. (1987) Angiotensin I converting enzyme inhibitory activity of the C-terminal hexapeptide of $\alpha_{\mathrm{s} 1}$-casein. Agric. Biol. Chem. 51, 2557-2561

Matheis G., Penner M.H., Feeney R.E. \& Whitaker J.R. (1983) Phosphorylation of casein and lysozyme by phosphorus oxychloride. $J$. Agric. Food Chem. 31, 379-387

Mathur B.N. \& Shahani K.M. (1979) Use of total whey constituents for human food. $J$. Dairy Sci. 62, 99-105

Mattarella N.L. \& Richardson T. (1983) Physicochemical and functional properties of positively charged derivatives of bovine B-lactoglobulin. J. Agric. Food Chem. 31, 972-978

Mattarella N.L., Creamer L.K. \& Richardson T. (1983) Amidation or esterification of bovine B-lactoglobulin to form positively charged proteins. J. Agric. Food Chem. 31, 968-971

Matthews M.E. (1984) Whey protein recovery processes and products. J. Dairy Sci. 67, 26802692

Maubois J.L. (1984) Separation, extraction and fractionation of milk protein components. Lait $64,485-495$

Maubois J.L. \& Brulé G. (1982) Utilisation des techniques à membrane pour la séparation, la purification et la fragmentation des protéines laitières. Lait 62, 484-510

Maubois J.L. \& Léonil J. (1988) Nouvelles utilisations diététiques et para-pharmaceutiques des protéines laitières. Colloque National : "Nouvelles Utilisations du Lait", Québec, Canada

Maubois J.L., Pierre A., Fauquant J. \& Piot M. (1987) Industrial fractionation of main whey proteins. Bull. FIL 212, 154-159

Mendy F. (1984) Fragmentation des protéines laitières. Biofutur, 24, 60-61

Meisel H. \& Frister H. (1988) Chemical characterization of bioactive peptides isolated from in vivo digests of casein. Hannah Research Institute Casein Conference, Ayr, Scotland
Migliore-Samour D., Floch F. \& Jolles P. (1988) Biologically active peptides of casein implicated in immunomodulation. Hannah Research Institute Casein Conference, Ayr, Scotland

Mirabel B. (1981) Possibilité d'application au lactosérum de nouveaux procédés de précipitation ou de fractionnement des protéines. I. Procédés par adsorption : production d'isolats de protéines par la technique «Sphérosil». Tech. Lait 952, 37-40

Mirabel B. \& Goudal R. (1981) Actualités dans le domaine des technologies à échangeurs d'ions pour la séparation et la purification des protéines laitières. Application du procédé Sphérosil au traitement du lactosérum doux. Rev. Lait. Fr. 400, 77-81

Modler H.W. (1985a) Functional properties of nonfat dairy ingredients. A review. Modification of products containing casein. J. Dairy Sci. 68 , 2195-2205

Modler H.W. (1985b) Functional properties of nonfat dairy ingredients. A review. Modification of lactose and products containing whey proteins. J. Dairy Sci. 68, 2206-2214

Modler H.W. \& Emmons D.B. (1977) Properties of whey protein concentrate prepared by heating under acidic conditions. J. Dairy Sci. 60, 177-184

Modler H.W. \& Harwalkar V.R. (1981) Whey protein concentrate prepared by heating under acidic conditions. 1. Recovery by ultrafiltration and functional properties. Milchwissenschaft 36, 537-542

Modler H.W. \& Jones J.D. (1987) Selected processes to improve the functionality of dairy ingredients. Food Technol. 41, 10, 114-117

Monti J.C. \& Jost R. (1978) Enzymatic solubilization of heat denatured cheese whey protein. J. Dairy Sci. 61, 1233-1237

Moor T.W., Peng I.C. \& Lonergan D.A. (1988) Chemical properties of cryocasein. J. Food Sci. 53, 1687-1693

Moor T.W., Peng I.C. \& Lonergan D.A. (1989) Functional properties of cryocasein. J. Dairy Sci. 72, 815-828

Moor T.W., Peng I.C. \& Lonergan D.A. (1988) Chemical properties of cryocasein. J. Food Sci. 53, 1687-1693

Moor T.W., Peng I.C. \& Lonergan D.A. (1989) Functional properties of cryocasein. $J$. Dairy Sci. $72,815-828$

Morr C.V. (1979a) Utilization of milk proteins as starting material for other foodstuffs. J. Dairy Res. 46, 369-376 
Morr C.V. (1979b) Conformation and functionality of milk proteins. ACS Symposium Series. 92 A (Pour El Ed.), American Chemical Society, Washington DC, pp. 65-79

Morr C.V. (1981) Emulsifiers : milk proteins. ACS Symposium Series. 147, (J.P. Cherry, ed.) American Chemical Society, Washington DC, pp. 201-215

Morr C.V. (1982) Functional properties of milk proteins and their use as food ingredients. In : Developments in Dairy Chemistry. 1. Proteins. (P.F. Fox, ed.) Applied Science Publishers, Londres et New York, pp. 375-399

Morr C.V. (1985) Functionality of heated milk proteins in dairy and related foods. J. Dairy Sci. 68, 2773-2781

Morr C.V., Nielsen M.A. \& Coulter S.T. (1967) Contrifugal Sephadex procedure for fractionation of concentrated skimmilk, whey and similar biological systems. J. Dairy Sci. 50, 305-306

Muller L.L. (1982) Manufacture of caseins, caseinates and coprecipitates. In : Developments in dairy chemistry. 1. Proteins (P.F. Fox, ed.) Applied Science Publishers, Londres et New-York, pp. 315-337

Mulvihill D.M. \& Fox P.F. (1983) Assessment of the functional properties of milk protein products. Bull. FIL 209, 1-11

Nakai S. \& Li-Chan E. (1985) Structure modification and functionality of whey proteins : quantitative structure-activity relationship approach. J. Dairy Sci. 68, 2763-2772

Noznick P.P. (1982) Dairy ingredients in food. Bull. FIL 142, 60-66

Olson N.F. (1982) Broadening whey protein use. Dairy Field 165, 1, 76

Paquet D., Thou K.S. \& Alais C. (1978) Obtention de produits moussants alimentaires par hydrolyse ménagée des protéines du lactosérum de fromagerie. Ind. Alim. Agric. 95, 161168

Paquet P. (1988) Communication personnelle. Colloque national : «Nouvelles utilisations $d u$ lait", Québec, Canada

Parkinson C.J. (1984) Uses for dairy ingredients in baked products. J. Soc. Dairy Technol. 37 (4), 125-127

Pearce R.J; (1987) Fractionation of whey proteins. Bull. FIL 212, 150-153

Pierre A. \& Fauquant J. (1986) Principes pour un procédé industriel de fractionnement des protéines du lactosérum. Lait 66, 405-419
Poznanski S., Ozimek G. \& Smietana Z. (1982) Thermostable textured milk proteins. Bull. FIL 147,46

Puigserver A.J., Sen L.C., Clifford A.J., Fenney R.E. \& Whitaker J.R. (1979) A method for improving the nutritional value of food proteins : covalent attachment of amino acids. In : Nutritional Improvement of Food and Feed Proteins (M. Friedman, ed.), Plenum Press, New York et Londres, pp. 587-612

Racotta V., Humbert G. \& Alais C. (1981) Nouvelles voies d'utilisation des protéines lactosériques. IV. Protéines thermocoagulées pour la supplémentation d'aliments locaux dans les pays défavorisés. Tech. Lait 952, 77-79

Reimerdes E.H. \& Lorenzen P.C. (1983) New results about milk protein emulsifiers. in : Proceedings of IDF Symposium : Physico-chemical Aspects of Dehydrated Protein-rich Milk Products, Helsingor, Denmark, pp. 70-93

Renz-Schauen A. \& Renner E. (1987) Fortification of nondairy foods with dairy ingredients. Food Technol. 41, 10, 122-127

Ribadeau-Dumas B. (1981) Actualités dans le domaine de la connaissance de la structure et des propriétés biochimiques des protéines laitières. Rev. Lait. Fr. 400, 17-32

Richert S.H., Morr C.V. \& Cooney C.M. (1974) Effects of heat and other factors upon foaming properties of whey protein concentrates. $J$. Food Sci. 39, 42-48

Roger L., Brulé G. \& Maubois J.L. (1981) Nouvelles voies d'utilisation du lactosérum. I. Hydrolyse des protéines du lactosérum. Intérêt thérapeutique. Tech. Lait 952, 65-67

Sanderson W.B. (1988a) Dairy Ingredients for the food industry. Bull. FIL 224, 33-35

Sanderson W.B. (1988b) Situation générale des ingrédients laitiers. Colloque national : «Nouvelles utilisations du lait». Québec, Canada

Sanderson W.B. (1988c) Utilisation des ingrédients laitiers dans les charcuteries. Colloque national : “Nouvelles utilisations du lait», Québec, Canada

Saint Paul F., Humbert G., Paquet D. \& Linden G. (1984) Hydrolyse enzymatique des protéines laitières industrielles : incidences sur leur solubilité. Sci. Aliment 4, hors série 111, 59-264

Segalen P. (1981) Actualités dans le domaine de la technologie de préparation des caséines et caséinates. Rev. Lait Fr. 400, 83-89 
Shimizu M., Lee S.W., Kaminogawa S. \& Yamauchi K. (1984) Emulsifying properties of an $\mathrm{N}$-terminal peptide obtained from the peptic hydrolysate of $\alpha_{\mathrm{s} 1}$-casein. J. Food Sci. 49, 1117-1120

Slack A.W., Amundson C.H. \& Hill C.G. (1986a) Production of enriched $\alpha$-lactalbumin whey protein fractions. J. Food Proces. Preserv. 10, 1930

Slack A.W., Amundson C.H. \& Hill C.G. (1986b) Foaming and emulsifying characteristics of fractionated whey protein. J. Food Proces. Preserv. 10, 81-88

Southward C.R. \& Goldman A. (1975) Co-precipitates. A review. N.Z. J. Dairy Sci. Technol. 10, 101-112

Southward C.R. \& Goldman A. (1978) Co-precipitates and their application in food products. II. Some properties and applications. N.Z. J. Dairy Sci. Technol. 13, 97-105

Sternberg M., Chiang J.P. \& Eberts N.J. (1976) Cheese whey proteins isolated with polyacrylic acid. J. Dairy Sci. 59, 1042-1050

Swaisgood H.E. (1982) Chemistry of milk protein. In : Developments in Dairy Chemistry. 1. Proteins (Fox P.F., ed.) Applied Science Publishers, Londres et New York, pp. 1-59

Thompson L.U. \& Reyes E.S. (1980) Modification of heat coagulated whey protein concentrates by succinylation. J. Dairy Sci. 63, 715721

Thompson L.U. \& Reniers D.J. (1982) Succinylated cheese whey protein concentrates in coffee whitener and salad dressing. J. Dairy Sci. $65,1135-1140$
Thompson L.U. \& Baker L.M. (1983) Influence of succinylated whey protein concentrate on farinograph characteristics and bread quality. Cereal Chem. 60, 71-73

Thompson L.U., Reniers D.J. \& Baker L.M. (1982) Succinylated whey protein concentrates in meat patties and wieners. J. Dairy Sci. 65, 1715-1721

Tinbergen B.J. (1988) A market for milk proteins. Bull. FIL 224, 22-26

To B., Helbig N.B., Nakai S. \& Ma C.Y. (1985) Modification of whey protein concentrate to simulate whippability and gelation of egg white. Can. Inst. Food Sci. Technol. J. 18, 150-157

Triballat (1979) Procédé et installation pour la préparation de la caséine à partir du lait et produits ainsi obtenus. Brevet Fr. 2418426

Van Den Hoven M. (1987) Functionality of dairy ingredients in meat products. Food Technol. 41, 10, $72-77$

Van de Voort F.R., Stanley D.W. \& Edamura R. (1984) Improved utilization of dairy proteins : coextrusion of casein and wheat flour. J. Dairy Sci. $67,749-758$

Verhey J.G.P. (1986) Physical properties of dried milk in relation to chocolate manufacture. Neth. Milk Dairy J. 40, 261-268

Wenner V. (1982) L'utilisation des protéines du lait à des fins diététiques et thérapeutiques en alimentation humaine. Lait 62, 549-565

West S.I. (1984) What does the food industry require of dairy ingredients? J. Soc. Dairy Technol. 37, 4, 117-119

Woo S.L. \& Richardson T. (1983) Functional properties of phosphorylated B-tactoglobulin. J. Dairy Sci. 66, 984-987 